\title{
Algunas reflexiones sobre la regulación de la forma contractual en el código civil de 1984
}

\author{
Marco Antonio Ortega Piana \\ Abogado por la Pontificia Universidad Católica del Perú. \\ Profesor de la Facultad de Derecho de la Universidad \\ de Lima y de la Carrera de Derecho Corporativo de la Universidad ESAN.
}

\section{SUMARIO:}

I. Introducción.

II. Marco conceptual general.

III. Perfeccionamiento Constitutivo.

IV. Marco normativo aplicable al Perfeccionamiento Contractual.

V. Pacto sobre Perfeccionamiento Constitutivo real.

VI. Pacto sobre Perfeccionamiento Constitutivo formal o solemnidad convencional.

VII. Modificaciones a los contratos sujetos a determinada forma.

VIII.A modo de conclusión. 


\title{
RESUMEN:
}

En el presente artículo, el autor compartirá algunas reflexiones sobre la regulación de la forma contractual en el Código Civil Peruano de 1984, postulando que, en algunos aspectos muy puntuales, se justifica una precisión de los respectivos enunciados legislativos.

Palabras clave: Derecho Civil, Código Civil, Contratos, Perfeccionamiento Contractual.

\begin{abstract}
:
In the following article, the author will provide an analysis regarding the regulation of the contractual form in the Peruvian Civil Code of 1984, postulating that, in certain key aspects, precisions of the legislative texts are justified.

Keywords: Civil Law, Civil Code, Contracts, Completion of Contract.
\end{abstract}

\section{INTRODUCCIÓN}

El presente trabajo representa el pago de una deuda, y como dice el refrán, "No hay plazo que no se cumpla, ni deuda que no se pague". Hace ya un buen tiempo, gracias a la oportunidad brindada por ADVOCATUS, tuve la oportunidad de publicar un trabajo sobre la forma contractual ${ }^{1}$; empero, por el mérito de la investigación que obliga permanentemente el ejercicio de la docencia, por el intercambio de opiniones con distintos colegas y alumnos, y de manera fundamental por la propia insatisfacción respecto de ciertos aspectos expuestos en su oportunidad, no solo corresponde precisar, sino rectificar, algunos de sus postulados y conclusiones, sin perjuicio de proponer algunas reflexiones adicionales.

Por ello, atendiendo a la gentil invitación de ADVOCATUS, he estimado necesario no extender por más tiempo el pago del débito referido, confiando siempre que el presente trabajo sea finalmente de utilidad para quienes tengan interés en el derecho contractual.

Sin perjuicio de lo expresado, que representa una justificación personal, debe también destacarse que, encontrándose nuevamente el Código Civil de 1984 bajo un proceso de reforma, conviene releer muchas de sus disposiciones para determinar las acciones a seguir. En ese proceso de reforma han surgido muchas voces sobre qué y por qué modificar al señalado cuerpo normativo, habiéndose presentado propuestas de múltiples contenidos y diversos calibres, las que deberán ser debidamente evaluadas para decidir si se justifica realmente modificar o no las reglas establecidas, o sobre si sería suficiente aplicar al actual texto legal lo que algún profesor de Derecho denomina una "sana interpretación", siguiendo la más autorizada doctrina sobre la materia. Y es que deberíamos tener presente que lo ideal sería sólo plantear modificaciones necesarias, indispensables para prevenir conflictos, sobre la base de lo que se aprecia en el debate académico nutrido de la información proveniente de la realidad misma, de la experiencia jurisdiccional.

Atendiendo a lo expresado, este trabajo está orientado a compartir algunas reflexiones sobre la regulación de la forma contractual en el Código Civil de 1984, postulando que en algunos aspectos muy puntuales se justifique probablemente una precisión de los respectivos enunciados legislativos.

\section{MARCO CONCEPTUAL GENERAL}

Todo contrato es un acuerdo de voluntades, pero no corresponde a cualquier acuerdo de voluntades. La voluntad coincidente debe poseer contenido patrimonial, y de manera específica, debe ser de naturaleza obligacional, conforme

1. ORTEGA PIANA, Marco Antonio. "Algunos comentarios sobre la formalidad contractual". En: ADVOCATUS $\mathrm{N}^{\circ} 13$. Lima: 2005, pp. 169-187. 
lo sanciona expresa y puntualmente la normativa en materia de objeto contractual ${ }^{2}$.

Ya hemos tenido oportunidad de expresar ${ }^{3}$ que dicha exigencia legislativa se sustenta básicamente en dos razones: la primera de ellas es que el contrato es un instrumento para el intercambio o tráfico patrimonial, representando un vehículo para fines de colaboración entre los agentes. Lo que interesa a la parte que contrata es lograr algo de su contraparte, hay un interés conductual, por lo que el establecimiento del respectivo vínculo obligacional debe permitir que el compromiso prestacional pueda ser efectivamente demandado, derivándose una serie de consecuencias legales en caso de incumplimiento - relativo o absoluto-, las mismas que están referidas en los artículos 1219 y 1428 — primer párrafo- del Código Civil.

El contrato crea, regula, modifica o extingue relaciones crediticias en las que resulta indispensable la acción u omisión de una de las partes - sujeta al débito- para satisfacer el interés de su contraparte - titular del crédito. Así, por elemental exclusión, los acuerdos patrimoniales no obligacionales no son contratos, pero ello no significa que carezcan de relevancia o protección jurídica, siendo convenios sujetos a reglas distintas, como es el caso de la opción.

La segunda de las indicadas razones, que pareciera haber sido olvidada, o de la cual se pretende prescindir por una supuesta falta de concordancia legislativa al compulsar las reglas de derechos reales con las del derecho de contratos, es que los contratos sólo pueden generar efectos obligacionales, no siendo posible que generen por sí mismos efectos reales. En otras palabras, destacándose que lo señalado opera en especial tratándose de los contratos de cambio, la celebración del respectivo negocio no transfiere por sí misma derecho real alguno titularidad que está caracterizada por una oponibilidad erga omnes - , sino que compromete a transferirlo, de tal manera que, conforme al diseño legislativo de 1984, que es además consistente con la legislación civil anterior, estamos adscritos al régimen del título y modo, más allá de la innegable discusión existente sobre cuál sería el modo en materia inmobiliaria.

El contrato genera una relación jurídica específica, obligacional, de la cual se derivará en su oportunidad la respectiva transferencia de propiedad: relación causa-efecto. En tal virtud, para quienes postulan en nuestro medio la existencia de un sistema dual, obligacional -en materia mobiliaria-y traslativo - en materia inmobiliaria- para fines de la transferencia convencional de propiedad, correspondería releer el artículo 949 del Código Civil en función a los antecedentes que dieron origen a su redacción, teniendo en consideración el principio de relatividad contractual y el carácter autosatisfactivo -eficacia absoluta- que debe presentar todo derecho real para que sea considerado como tal. Una propiedad que no resulta oponible corresponderá a un derecho relativo, más no a uno absoluto.

Por una elemental cuestión de pertinencia, no corresponde desarrollar dicho tema en el presente trabajo, remitiéndonos no sólo al texto legislativo sino a las explicaciones proporcionadas por los profesores Arias Schreiber y De la Puente, responsables de la redacción del Código Civil de 1984 sobre la materia, las mismas que están consideradas, entre otras, en el trabajo anteriormente señalado. Podremos compartir o no dichas explicaciones, pero no podemos definitivamente ignorarlas.

Volviendo a nuestro tema, con relación a este acuerdo de voluntades patrimonial de natu-

2. Artículo 1402 y siguientes del Código Civil de 1984. Conforme a ello, no es casual que la regulación de contratos, tanto parte general como parte especial, conste en el Libro VII del Código Civil: Fuentes de las Obligaciones.

3. Cfr: ORTEGA PIANA, Marco Antonio. "Objeto contractual y transferencia de propiedad". En: Forseti № 2. Lima: 2014, pp. 10-46. Disponible en: <http://www.forseti.pe/revista/2014-numero-2>, y AA.VV., "Estudios críticos sobre el Código Civil - Análisis crítico y actual sobre sus bases dogmáticas y de su aplicación práctica". Lima: 2014, Gaceta Jurídica, pp. 423-471. 
raleza necesariamente obligacional surge la cuestión sobre cómo se entiende celebrado. La cuestión no radica en cuándo se entiende celebrado, porque en función a la naturaleza recepticia de las declaraciones volitivas formativas de un contrato, el mismo queda celebrado cuando la declaración del aceptante es finalmente conocida por el oferente, conforme lo sanciona el artículo 1373 de nuestro Código Civil. Nuestra inquietud está orientada más bien a cómo se entiende formado o generado el consentimiento.

Y para ello debe considerarse que el ordenamiento tamiza lo que se entiende por consentimiento, en función a diversas consideraciones respecto de las cuales las partes están subordinadas, ya que se contrata sobre la base de la autonomía privada, esto es, del poder negocial reconocido por el ordenamiento a los agentes, atendiendo a la existencia de un interés merecedor de tutela, lo cual a su vez les permite vincularse y autorreglamentar sus intereses patrimoniales.

Debe además considerarse que, de concluirse que no se ha formado finalmente el consentimiento, no se estará en un escenario de invalidez - a título de nulidad-, sino ante uno de inexistencia, dado que el acuerdo de voluntades constitutivo del contrato no se ha generado.

La noción de perfeccionamiento constitutivo o formativo permite entender la manera en que debe ser expresada la voluntad para que genere el efecto jurídico representado y deseado por las partes: el contrato, como fuente de obligaciones. Es la ley la que determina cuándo se está o no frente a un acuerdo contractual, sobre la base que la posibilidad de contratar no corresponde a un derecho natural, sino que es un derecho derivado, reconocido por el ordenamiento, atendiendo a las consecuencias que se desprenderán del mismo, estimándose beneficiosas para la sociedad. Como bien se ha afirmado, las partes tienen capacidad autorreguladora, normativa, en la medida que le es otorgada por la ley 4 .

Es el ordenamiento jurídico el que define, positiva o negativamente, la capacidad para contratar, el consentimiento y los contenidos negociales, sirviéndose excepcionalmente de normas imperativas o inderogables, algunas de las cuales interesan inclusive al orden público.

Conforme a ello, la ley establece que todo contrato demanda formativamente de un consentimiento, la cuestión será qué se entiende por consentimiento, y si las partes tienen algún protagonismo en dicha definición.

\section{PERFECCIONAMIENTO CONSTITUTIVO}

Para determinar cómo se genera el consentimiento, debe tenerse presente que el derecho, como toda obra humana, ha evolucionado en el tiempo, ya que al ser una disciplina ordenadora debe sintonizar con la realidad, con las necesidades del tráfico. Ya ha quedado ampliamente superada la exigencia de acuerdos solemnes, casi rituales, para que pueda concluirse en la celebración contractual ${ }^{5}$. Atendiendo a que el contrato es simplemente un instrumento, que corresponde al acuerdo en sí, más allá de los efectos que se

4. "Recordemos que según esta teoría la autonomía privada, o sea el poder reconocido a las personas de crear relaciones jurídicas obligatorias entre sí, no tiene su origen en la libertad humana sino en el ordenamiento jurídico. Es este ordenamiento el que, teniendo en principio la potestad de regular todas las relaciones jurídicas, se abstiene de ejercer parte de esa potestad -la relacionada con la regulación de las relaciones jurídicas patrimoniales entre los particulares - y la delega —entendiendo el verbo delegar en su acepción de concesión de atribución- a estos particulares para que ellos la ejerzan libremente dentro de determinados límites. Respetados estos límites, la autonomía privada es absoluta, en el sentido que las relaciones jurídicas creadas a su amparo son obligatorias". DE LA PUENTE Y LAVALLE, Manuel. "El Contrato en General - Comentarios a la Sección Primera del Libro VII del Código Civil", Tomo I. Lima: Palestra Editores, 2011, p. 231.

5. "Ha sido señalado muchas veces que los Derechos primitivos fueron fundamentalmente formalistas. Las mentalidades primitivas no comprendieron la fuerza obligatoria de la voluntad. Por ello la creación de especiales obligaciones o vínculos contractuales se ligaba siempre con fórmulas mágicas o rituales y con especiales ceremonias de valor religioso 
desprendan de su celebración, y siendo que es un vehículo para lograr el intercambio económico de bienes y servicios, se admite modernamente que el contrato queda celebrado - como regla general- por la exteriorización del simple acuerdo de voluntades, apreciándose así la coincidencia volitiva entre oferente y aceptante. Ello corresponde al principio formativo general de la consensualidad contractual.

Dicha regla bien puede ser enunciada — como tantos conceptos jurídicos - de manera positiva o negativa, como anverso y reverso de una misma moneda. Lo primero corresponde a lo ya señalado: para que se tenga por celebrado al contrato, resulta suficiente el solo acuerdo de voluntades, para cuyo efecto las partes pueden expresarse de la manera que estimen por conveniente, de forma expresa - escrita u oral- o tácita. Lo segundo es lo mismo, pero desde otra perspectiva: la celebración del contrato no demanda que las declaraciones volitivas formativas deban observar una forma específica. Esta regla corresponde a la denominada libertad de forma.

Pero se trata de la regla general, porque existe una excepción, asociada a la noción misma de la autonomía privada en materia negocial: la ley. El ordenamiento reconoce a las partes el poder negocial de contratar, de autorregular sus intereses para fines del intercambio económico, de obligarse, pero las partes no deben cruzar las fronteras establecidas, siendo que la ley se ha reservado la posibilidad de exigir que, en algunos casos, la voluntad de las partes sea declarada, exteriorizada, de determinada manera para que se tenga como existente $y$, en consecuencia, en la medida que sea además una declaración válida, para que pueda generar los correspondientes efectos jurídicos. Esta regla formativa implica, por consiguiente, desde una aproximación legal, que el consentimiento puede ser jurídicamente algo más que un simple acuerdo de voluntades. Es el caso cuando se subordina la celebración negocial a la necesaria observancia de una formalidad, esto es, a una exigencia de forma específica, dado que la ley demanda que la voluntad común sea declarada necesariamente por las partes bajo cierta forma o manera, la misma es exigida bajo sanción de nulidad.

Adviértase que tenemos al frente a tres categorías negociales: existencia / inexistencia, validez / invalidez y eficacia / ineficacia. Para que exista todo contrato debe mediar un acuerdo de voluntades, ambos se identifican ontológicamente; ese acuerdo es el consenso o consentimiento, entendiéndose como tal a la simple coincidencia volitiva, salvo que se exija de algo más para admitir su configuración.

De haberse generado el respectivo consentimiento, el mismo será válido en la medida que se cumpla con los respectivos requisitos, evitándose así incurrir en causal de invalidez sea a título de nulidad o anulabilidad. Sobre el particular, recuérdese que somos históricamente tributarios del derecho francés, por lo que estamos a la regla conforme a la cual no hay nulidad - sea absoluta o no- sin sanción legal. La invalidez afecta la eficacia del negocio, la afecta estructuralmente, negándola — nulidad - o retirándola — anulabilidad-.

Por último, existiendo un válido acuerdo de voluntades, el mismo será eficaz, surtirá efectos,

o semi-religioso. Este esquema puede encontrarse en el Derecho Romano primitivo —nexum, sponsio, stipulatio- El Derecho Romano, sin embargo, evolucionó constantemente hacia fórmulas cada vez más espiritualizadas, llegando a admitir, como sabemos, la categoría del contrato consensual y dotando de una cierta eficacia a los pactos. Sin embargo, el formalismo primitivo no llegó a desaparecer del todo. Las formalidades orales fueron poco a poco sustituidas por formas escritas y, acaso, el formalismo que al principio tuvo un carácter constitutivo fue lentamente pasando a ser un formalismo con valor probatorio.

(...)

En la Baja Edad Media, sin embargo, y especialmente en las ciudades, las necesidades del tráfico comercial impusieron una liberación de la contratación respecto de las rígidas formas anteriores y llegó a consagrarse el llamado contrato consensual romano-italiano, que fue jurídicamente recibido en toda Europa". DIEZ-PICAZO, Luis. "Fundamentos del Derecho Civil Patrimonial". Madrid: Editorial Civitas, 1996, p. 251. 
más allá que la exigibilidad total o parcial de lo convenido sea inmediata o diferida.

Si no se ha alcanzado el consentimiento, es manifiesto que no se ha celebrado contrato alguno; conforme a ello, resultará impertinente referirnos a las categorías de invalidez o ineficacia. Empero, podría ser que se hubiese alcanzado un acuerdo, pero por incurrir en un defecto formativo, por carencia de un requisito estructural, esencial, aquél carezca de todo efecto propio o directo ${ }^{6}$, o sea susceptible de perderlos, de manera que el acuerdo sea nulo, o anulable.

Existe abundante literatura jurídica sobre este tema del perfeccionamiento constitutivo. Nos vamos a referir a dos conocidos autores. Vidal $^{7}$ sostiene que, en determinado sentido, todo acto jurídico - y el contrato lo es- demanda de voluntad, pero que también corresponde a que la misma sea exteriorizada de alguna manera, expresa o tácitamente, para que sea conocida y despliegue efectos jurídicos, ya que no hay actos sin forma, de manera que en ese sentido se está ante actos de forma prescrita y actos de forma voluntaria. Bajo el mismo enfoque, Mosset $^{8}$ expresa:
"Si entendemos que la forma es, al decir de Geny, "el elemento exterior y sensible destinado a encuadrar las circunstancias inmateriales de la naturaleza de los actos" o la caracterizamos, con Barbero, como el "modo naturalmente idóneo, cualquiera que sea, como se hace la manifestación negocial", es evidente que todos los negocios deben ofrecer una forma pues de lo contrario su intención no sería reconocible. De donde la dicotomía formales y no formales, sobre la base de este concepto, pierde todo sentido".

Y a continuación prosigue el señalado civilista argentino:

"Pero el problema es otro: la distinción se funda en una acepción más restringida y más concreta del vocablo forma, puesto que a veces no cualquier modo es relevante para que la manifestación consiga su efecto; se agrega entonces un matiz de exigencia particularizada. Se denominan negocios formales a aquellos cuya solemnidad es taxativamente prefijada por la ley - forma dispuesta o tasada-, no formales a aquellos cuya exteriorización es libre y que pueden,

6. MORALES HERVIAS, Rómulo. Patologías y remedios del contrato, Jurista Editores, Lima, 2011, p. 202. En efecto, el referido autor afirma: "La invalidez expresa un juicio negativo de valor, de disconformidad, entre el acto de autonomía privada, como valor, y el orden jurídico, también como valor. Invalidez es disvalor del acto de autonomía privada. De la invalidez resulta normalmente la ineficacia, siempre que la incompatibilidad valorativa entre el acto de autonomía privada y el orden jurídico sea tal que el orden jurídico rechace que el acto de autonomía privada produzca sus efectos jurídicos propios". Ahora bien, generándose la dicotomía de efectos jurídicos propios o no, merece destacarse que el acto jurídico nulo puede generar efectos colaterales o meramente fácticos, como sería el caso de una restitución de lo que hubiese sido ejecutado en su oportunidad, al carecerse de un título sustentatorio válido. Sobre esto último, merece considerarse que "(...) resultaría erróneo afirmar que el negocio nulo equivale a la "nada jurídica". En efecto, es absolutamente indispensable poner de manifiesto que el acto de autonomía privada afectado de nulidad produce ciertos efectos jurídicos reflejos, secundarios o marginales que, desde luego, no resultan equiparables a las consecuencias finales que despliegan los negocios válidos y eficaces en sentido estricto. En otros términos, tal como lo ha advertido ya un sector de la doctrina nacional, el negocio nulo es jurídicamente relevante en la medida que produce efectos derivados del hecho mismo de su celebración o ejecución". VÁSQUEZ REBAZA, Walter. "La inexistencia del negocio jurídico. ¿Duplicación inútil, hipótesis de escuela o genuina categoría operativa?". En: Revista Jurídica del Perú, tomo 141. Trujillo: Editorial Normas Legales, 2012, p. 172

7. VIDAL RAMÍREZ, Fernando. “El Acto Jurídico”. Lima: Pacífico Editores, 2016, p.131. El profesor Vidal va a destacar, de manera complementaria, que "La voluntad interna, una vez formada por el discernimiento, la intención y la libertad, debe exteriorizarse y, por eso, viene a ser el sustrato de la voluntad manifestada. La voluntad interna, también llamada voluntad real, aún (sic) cuando esté conjugada por el discernimiento, la intención y la libertad, no es suficiente para la formación de la voluntad jurídica y darle validez al acto jurídico que se quiere celebrar, pues este requiere de la exteriorización de la voluntad interna mediante la manifestación" Op. cit., p. 134.

8. MOSSET, Jorge. "Contratos". Buenos Aires: Rubinzal - Culzoni Editores, 1998, p. 85 
por lo tanto, realizarse en cualquiera "de las que el uso social considera instrumento de manifestación admisible e inequívoca"9 (el subrayado es nuestro).

Sobre la base que sólo tiene significado jurídico aquello que es exteriorizado, declarado, los contratos quedarán celebrados, perfeccionados constitutivamente -más allá que pretendan crear, regular, modificar o extinguir relaciones obligatorias-, según sea que se exija o no que la voluntad común sea expresada de cierta manera.

Así, al consentimiento contractual, en términos legales, podemos clasificarlo como simple o como calificado.

Conforme ya hemos expresado, la regla general es que el derecho reconoce al acuerdo de voluntades más allá de la forma en que sea expresado; es así que el contrato puede ser celebrado bajo el régimen de libertad de forma, aplicándose las distintas maneras de expresar la voluntad, reconocidas en el artículo 141 de nuestro Código Civil. Así, por ejemplo, un contrato de compraventa puede ser celebrado verbalmente, así como también por escrito, o que una sola de las dos declaraciones formativas - sea la oferta o la aceptación-conste por escrito; asimismo, la forma escrita puede ser estimada o graduada libremente, pudiendo constar las declaraciones mediante simple documento o por escritura pública. En todo caso, nada impide admitir que el contrato de compraventa quede celebrado conductualmente, mediante la ejecución de comportamientos concluyentes, susceptibles de ser valorados de una determinada y cierta manera, e inclusive mediante la asignación de valor al silencio. Bajo este régimen de libertad de forma, siempre en el marco de la autonomía privada, las partes pueden subordinar los efectos del negocio, sea de manera total o parcial, a la observancia de una determinada forma; por ejemplo, pueden establecer que el respectivo contrato sólo adquirirá eficacia una vez suscrita la correspondiente escritura pública.

Por necesidades comerciales, y bajo el imperio de una orientación filosófica que sustentó finalmente la formación del principio decimonónico de la autonomía de la voluntad, en que se privilegiaba una irrestricta libertad de las personas, la regla general de perfeccionamiento constitutivo contractual es mediante consentimiento simple. $Y$ es que en general, en determinado contexto histórico, la voluntad individual era definitivamente el eje del derecho civil patrimonial.

El consentimiento simple corresponde a los denominados contratos consensuales, en que el consentimiento o consenso es suficiente para su celebración. Téngase presente, celebración, no ejecución, que es otro tema. La compraventa es el contrato consensual por excelencia, pero comparten la misma naturaleza múltiples contratos, entre otros, el arrendamiento, la prestación de servicios, la franquicia, el auspicio o "esponsorización", etc., se encuentren legislativamente tipificados o no.

Otro tema es si se está ante una válida celebración, para cuyo efecto hay que realizar un descarte, ya que se requiere determinar si se ha incurrido o no en una causal de nulidad o anulabilidad, escenario en el cual el ordenamiento no reconocerá que el acuerdo volitivo despliegue efectos propios, sea a título de nulidad o de anulabilidad, atendiendo a la gravedad de la afectación al sistema jurídico ${ }^{10}$.

Frente a la indicada regla general, la regla de excepción es que el derecho establezca que la declaración de voluntad sólo será existente $y$, por consiguiente, productora de efectos merecedores de tutela jurídica, en la medida que cumpla con la forma exigida de manera necesaria y no contingente o prescindible, por lo que la voluntad común deberá expresarse ineludiblemente de

9. MOSSET, Jorge. Op. cit., p. 85. La referencia a los negocios no formales es la que entendemos por consensuales o informales. Los negocios formales son los sujetos a solemnidad.

10. MORALES HERVIAS. Rómulo. Op. cit., p. 205. 
una determinada manera. Forma de la declaración se confunde, se identifica, con la declaración misma; conforme a ello, ante la inobservancia de la forma necesaria exigida, se entenderá que no ha habido declaración de voluntad por las partes, menos consenso, por lo que no se habrá generado relación contractual alguna.

De acuerdo a esta regla bajo comentario, el contrato sólo estará celebrado, válidamente celebrado, en la medida que las partes —ambas, al ser un acto plural- declaren su voluntad de una determinada o específica manera, la misma que es exigida bajo sanción de nulidad, esto último para destacarse que no se trata de una forma meramente probatoria y, por consiguiente, prescindible. Por ejemplo, la ley ${ }^{11}$ establece que el contrato de donación inmobiliaria se celebra mediante declaraciones contenidas en una escritura pública, bajo sanción de nulidad; ergo, si las partes exteriorizan su voluntad bajo una forma distinta, no se genera consentimiento alguno en el plano jurídico, por lo que no se producen los efectos que se habrían representado las partes. La declaración de voluntad debe, tiene que, expresarse necesariamente conforme a la respectiva formalidad, la misma que es documental.

Este tipo de perfeccionamiento constitutivo no es frecuente, pero se mantiene ante determinados negocios - conviene recordar que MOSSET hace referencia precedentemente a una solemnidad taxativamente prefijadaEste perfeccionamiento genético excepcional corresponde a los denominados contratos formales o sujetos a forma negocial ad solemnitatem o ad substantiam. Si ambas partes no observan la solemnidad correspondiente, no se habrá logrado el consentimiento, por lo que no despliega efectos lo inexistente.

Dos breves comentarios.
Si la forma solemne se confunde con la declaración de voluntad de las partes, en rigor, la inobservancia de la solemnidad derivaría en inexistencia antes que en invalidez, porque esta última categoría presupone un acto celebrado ${ }^{12}$; empero, nuestro Código Civil, zanja la cuestión estableciendo que la inobservancia de la forma legalmente exigida bajo sanción de nulidad es causal de invalidez a título de nulidad. Roma locuta, causa finita. En nuestra opinión, ello genera confusión al dimensionarse los alcances de las normas bajo comentario. No puede ser nulo lo inexistente, sólo puede serlo aquello que existe, dado que la nulidad es finalmente la negación de pleno derecho de efectos para algo que ha sido celebrado en oposición a reglas esenciales del ordenamiento. Además, si el negocio fuese nulo, lo cual presupondría existencia, a través de esta última se estaría asumiendo que ya hubo consentimiento, aunque el mismo no haya sido suficiente, siendo que esto último derivaría en admitir -indirecta e impropiamente- que el contrato ya se habría formado, dado que contrato no es sino consentimiento. Estimamos que este problema de categorías jurídicas, más allá de lo que enuncie en particular nuestro Código Civil, bien puede ser salvado - para fines genéticos-.

La inobservancia de la forma necesaria no es que conlleve nulidad, por haberse omitido seguir - para fines de la declaración comúnla forma establecida por ley bajo sanción de nulidad, sino que deriva en inexistencia, siendo que la referencia a la exigencia legal de una determinada forma bajo sanción de nulidad se realiza únicamente para diferenciarla de una forma que fuese simplemente probatoria. Es una referencia por exclusión, atendiendo a que si no se indica que se está ante una forma ad solemnitatem, se entendería que es meramente

11. Artículo 1625 del Código Civil de 1984.

12. ESPINOZA ESPINOZA, Juan. "Acto Jurídico Negocial. Análisis doctrinario, legislativo y jurisprudencial". Lima: Gaceta Jurídica, 2008, pp. 495-498. El autor destaca que la inexistencia es la falta de configuración del negocio o acto, a diferencia de la invalidez que presupone un negocio o acto que adolece de cierta patología —estructural— que deriva en que no genere los efectos jurídicos representados, los ya referidos efectos propios del negocio, sea por falta de elementos esenciales o por presentar vicios de la voluntad. 
ad probationem ${ }^{13}$. En materia de formación del consentimiento, entendemos que la ausencia de una declaración tal como lo pudiese exigir la ley, conlleva a que no se haya generado el consenso, elemento formativo esencial del negocio; en consecuencia, al no haber jurídicamente un acuerdo volitivo, el pretendido contrato es simplemente inexistente.

Al postular que la solemnidad es la declaración misma de voluntad, no resulta consistente lo expresado en el artículo 1352 de nuestro Código Civil: "Los contratos se perfeccionan por el consentimiento de las partes, excepto aquellos que, además, deben observar la forma señalada por la ley bajo sanción de nulidad", dado que la palabra "además" sugiere que al consentimiento - que ya estaría generado- se le exigiría un requisito adicional para formar al contrato, pero que ya hay consentimiento. Los alcances de este artículo han sido objeto de múltiples comentarios en los diversos intentos de reforma del actual Código Civil.

Postulamos que el consentimiento sólo se genera, legalmente, si se satisface la solemnidad; por ello nos referimos a un consentimiento calificado. Empero, no puede negarse que el Código Civil en diversas partes de su articulado diferencia entre la manifestación de voluntad -entiéndase declaración-y la necesidad de observar de manera necesaria cierta forma, bajo sanción de nulidad. Recuérdese que el lenguaje legislativo no es, ni tiene que ser, uno académico o científico ${ }^{14}$, de manera que bien puede entenderse que la norma en cuestión se refiere a que "Los contratos se perfeccionan por el consentimiento de las partes, excepto aquellos en que debe observarse la forma señalada por la ley bajo sanción de nulidad", lo cual reconocería que la regla general de perfeccionamiento genético es el consentimiento simple, salvo que se exija de un consentimiento calificado, observándose una solemnidad.

¿Debe modificarse el artículo 1352 del Código Civil? Estimamos que no se justifica. Ello además implicaría modificar un conjunto de artículos de dicho cuerpo normativo cuyo texto denota que habría el entendimiento que declaración de voluntad y forma esencial corresponden a conceptos distintos ${ }^{15}$, lo cual no es así necesariamente. En lo personal, confiamos en el buen criterio interpretativo jurisdiccional antes que el legislativo; la legislación —civil, en particularno debe ser objeto de modificaciones adjetivas, sino sólo para materias o temas sustanciales, cuando se llega a un punto en que la seguridad jurídica así lo requiera.

Si realizamos una breve comparación podemos advertir que los denominados contratos consensuales están bajo el régimen del consentimiento simple, y corresponden a la regla general de perfeccionamiento contractual, lo cual obedece a razones de celeridad para fines del tráfico ${ }^{16}$, según ya ha sido indicado. Las partes pueden expresar su coincidencia volitiva de la manera que estimen más conveniente a su interés. Por el contrario, los contratos formales, o solemnes, están bajo el régimen del consentimiento calificado, y corresponden a la regla de excepción del perfeccionamiento contractual,

13. Artículo 144 del Código Civil.

14. "En el léxico jurídico pueden distinguirse tres planos de análisis. El primero es el lenguaje natural u ordinario, que es el de la expresión usual, habitual, cotidiana o corriente de la sociedad. El segundo es el lenguaje de los hombres dedicados a la ciencia jurídica, que es un lenguaje característico que aspira a expresar con la mayor precisión posible las construcciones propias del derecho. El tercero es el lenguaje legislativo, es decir, el lenguaje del legislador, que si bien no debe ser ajeno al rigorismo semántico del jurista, tampoco debe apartarse demasiado del sentido de los vocablos encarnado en la comunidad". ALTERINI, Jorge, CORNA, Pablo María, ANGELANI, Elsa Beatriz y VÁSQUEZ, Gabriela Alejandra. "Teoría General de las Ineficacias". Buenos Aires: La Ley, 2000, p. 2.

15. Es el caso, entre otros, del artículo 140, atendiendo en particular a su inciso 4, así como el caso del artículo 219, incisos 1 y 6 .

16. Se aprecia la innegable influencia del derecho comercial; los negocios requieren ser celebrados de la manera más célere posible, por lo que la sola palabra es suficiente, sin perjuicio que puedan generarse formas probatorias. 
lo cual se sustenta en la necesidad de acreditar el consenso negocial de cierta manera, y no de otra, necesidad que se asocia a la seguridad jurídica ${ }^{17}$.Tratándose de la solemnidad contractual las partes están sujetas a una carga, en el sentido que sólo pueden expresar su coincidencia volitiva de la manera o forma documental establecida por ley bajo sanción de nulidad, lo cual corresponde a una regla de naturaleza imperativa $y$, por lo tanto, inderogable, por lo que carecen de libertad de forma.

En el marco de los contratos consensuales, en que cualquier forma seguida será meramente probatoria, no aplica la denomina "nulidad refleja" referida de alguna manera, negativamente, en el artículo 225 del Código Civil de 1984 - “No debe confundirse el acto con el documento que sirve para probarlo. Puede subsistir el acto aunque el documento se declare nulo"-. Así, por ejemplo, si se celebra una compraventa, siendo que la respectiva minuta es finalmente elevada a escritura pública, si de manera posterior se declara la nulidad de esta última, ello no debe afectar al negocio celebrado, sino únicamente a lo que era una forma probatoria. La compraventa fue celebrada válidamente, pudiéndose recurrir a la minuta para demostrar su celebración, o a cualquier otro medio probatorio que sea idóneo y pertinente. Cosa distinta ocurre tratándose de los contratos formales, en los que por definición sí opera la "nulidad refleja", conforme a la cual la nulidad del continente - documento- se extiende al contenido - negocio-.
Así, por ejemplo, si se celebra una donación inmobiliaria - lo cual exige de escritura pública, bajo sanción de nulidad, conforme al artículo 1625 de nuestro Código Civil-, si de manera posterior se declara la nulidad del indicado instrumento público, ello afectará insubsanablemente al pretendido negocio celebrado, ya que las declaraciones de voluntad no habrían sido rendidas mediante escritura pública; al no haber declaraciones, no habrá consenso alguno. Conforme ya hemos señalado, en rigor, se trata de un tema que trasciende de la invalidez, es un tema de inexistencia. En consecuencia, el documento, la minuta, que dio origen a la escritura pública de donación inmobiliaria, carece de valor, no evidencia consentimiento, porque entendemos que para el ordenamiento el consenso recién se configurará con la escritura pública.

Asimismo, en el marco de los contratos consensuales, en que se está a la regla de la libertad de forma, la celebración contractual puede demostrarse de cualquier manera idónea y pertinente, pudiéndose exigir inclusive que se otorguen formas probatorias específicas — sujeto esto a que existe una obligación de otorgarlas, sea legal o convencional-. Así, por ejemplo, celebrada verbalmente una compraventa inmobiliaria, el comprador puede ulteriormente exigir que, sobre la base del contrato ya celebrado, se le otorgue una escritura pública, para que su derecho esté documentado de mejor manera o para fines de una inscripción registral de ser el caso, de manera que pueda publicitar ade-

17. La solemnidad se extiende en nuestra legislación a tres supuestos documentales: simple forma escrita, forma escrita de fecha cierta y escritura pública, la dimensión del negocio vinculará cada una de ellas. Tratándose de la donación inmobiliaria, que corresponde a una liberalidad que deriva en una transferencia gratuita de propiedad, se demanda de escritura pública bajo sanción de nulidad, quizá más por tradición casi inmemorial que por una efectiva consideración económica del valor del bien comprometido. Como bien señala doctrina autorizada, la escritura pública no sólo permite autenticar la identidad y la declaración de voluntad del otorgante, sino que permite preservar su contenido en el tiempo, considerando el registro notarial correspondiente; siendo además que la configuración de la donación como contrato formal implica — en los hechos- generar un espacio temporal deliberativo para que el donante pueda representarse las consecuencias del acto a ser celebrado, dado que la suscripción de la minuta o de cualquier documento previo no lo compromete, quedando sólo obligado cuando es otorgada la escritura pública, completándose la suscripción con la intervención del notario público. "La razón política de esta imposición por parte del ordenamiento jurídico, estriba, como es sabido, en la exigencia de que las partes se vean forzadas por la necesidad del uso de la forma solemne, a reflexionar sobre la importancia económica del acto que van a realizar al estipular el contrato y se decidan a ello después de un maduro examen; es, por tanto, un medio indirecto de defensa de las partes contra su propia ligereza posible". MESSINEO, Francesco. "Doctrina General del Contrato". Tomo I. Buenos Aires: Ediciones Jurídicas Europa-América, 1986, p.151. 
cuadamente la transferencia de propiedad, o el derecho a la misma.

Cosa completamente diferente ocurre tratándose de los contratos formales, en los que declaración y forma necesaria se confunden, ya que satisfacer el requisito de forma esencial evidencia jurídicamente la formación del acuerdo volitivo. Así, por ejemplo, si se pretende haber celebrado una donación inmobiliaria mediante la suscripción de una minuta - desconociendo que la ley exige de escritura pública, bajo sanción de nulidad-, invocándose al artículo 1352 del Código Civil que hace mención al consentimiento de las partes, de manera posterior el supuesto donatario carecerá de legitimidad para demandar el otorgamiento de la escritura pública, dado que esta última "hace" al contrato mismo, forma jurídicamente el consentimiento, no siendo posible que se otorgue efectos vinculantes a un documento que carece de valor legal, ya que de lo contrario terminaría afectando la propia libertad de contratar del supuesto donante. Es más, el artículo 1412 del Código Civil no legitimaría a la señalada exigencia, dado que sólo puede compelerse la observancia de una determinada forma probatoria.

Y sin que por ello se pretenda agotar las diferencias de tratamiento jurídico entre ambas categorías de contratos, tratándose de los contratos consensuales - libertad de forma - es posible que se alcance el consentimiento inclusive mediante una aceptación tácita, o reflejada mediante comportamientos concluyentes, o por haberse acordado asignar determinado valor al silencio, lo cual no es definitivamente posible tratándose de los contratos formales, porque en estos últimos ambas declaraciones formativas de voluntad - oferta y aceptacióndeben expresarse observando necesariamente la forma documental legal exigida bajo sanción de nulidad, llámese simple forma escrita, forma escrita con fecha cierta o escritura pública, las cuales corresponden no sólo a declaraciones expresas sino escritas o documentales.

Conforme a ello, debemos destacar que siendo la consensualidad formativa la regla general de perfeccionamiento constitutivo contractual, el Código Civil vigente se coloca en dicho supuesto al regular la contratación en general, por lo que muchas de sus disposiciones resultan ajenas a los contratos solemnes, como son los casos, entre otros, de los artículos $1378^{18}, 1380^{19}$, y $1381^{20}$.

Por último, al lado de los contratos consensuales y formales tenemos también a los denominados contratos reales, los mismos que son diferentes - pese al parecido de su denominación- a los contratos con efectos reales. Téngase presente que la clasificación de los contratos en consensuales, formales y reales se relaciona al perfeccionamiento constitutivo, a la existencia del negocio.

Debe diferenciarse entre contratos reales - perfeccionamiento constitutivo, tema de formación del consentimiento- $\mathrm{y}$ contratos con efectos reales - perfeccionamiento operativo, tema de eficacia del consentimiento ya formado. Los contratos con efectos reales - o traslativos - se oponen a los contratos con efectos personales

18. Siendo que el contrato es consensual, esto es que se celebra bajo libertad de forma, nada impide que el oferente exprese al destinatario de la oferta que su eventual aceptación sólo tendrá valor y efectos en la medida que sea declarada de una determinada manera, la que será fijada libremente. Si el contrato fuese formal, ambas partes deberían necesariamente declarar su voluntad de la misma forma solemne.

19. La denominada aceptación tácita es conductual o derivada de un comportamiento concluyente que permita la representación indubitable de la voluntad; no se trata de una forma documental y no corresponde a una solemnidad, debiéndose además considerar que en materia de contratos formales, ambas partes deben observar por igual la forma necesaria o solemne.

20. El silencio corresponde a una declaración de voluntad sólo cuando la ley o el pacto así lo establecen; en rigor, el silencio es la falta de declaración, por lo que no puede aplicar a la formación de los contratos formales, porque los mismos demandan ineludiblemente que ambas partes expresen su voluntad observando una forma documental necesaria. 
— u obligacionales-, correspondiendo a una clasificación asociada fundamentalmente a la eficacia de los contratos de cambio, sobre cuándo se verifica la traslación de propiedad, lo cual presupone que el respectivo contrato haya sido válidamente celebrado.

En razón de la regulación expresa y puntual sobre el objeto contractual, atendiendo a los diversos tipos legales de los contratos de cambio, y considerando la identidad de las titularidades reales, que no están sujetas a relatividad alguna, nuestro Código Civil no admite la categorización de contratos con efectos reales o traslativos, descartando que el solo consenso permita una efectiva transferencia de propiedad. El contrato obliga, es la causa de la transferencia, pero no es la transferencia misma, y ello porque estamos adheridos al sistema del título y modo, sea en materia mobiliaria como inmobiliaria ${ }^{21}$.

Los contratos reales también están sujetos conceptualmente al régimen del consentimiento calificado, por más que no estén reconocidos en la legislación nacional, siendo que para la generación del consentimiento se requiere necesariamente de una determinada actuación, de manera puntual, de la entrega material de la cosa sobre la cual versan. No es que la falta de entrega corresponda a un tema de invalidez, de nulidad del contrato, sino que la falta de entrega impide la formación del consentimiento, por lo que ante la inexistencia del negocio debe concluirse que no hay generación de los efectos jurídicos reservados para la válida celebración de un contrato.

Conforme a ello, el contrato real sólo se entiende celebrado, formado el consentimiento, cuando una de las partes entrega a la otra la cosa sobre la cual recae el acuerdo, entrega que correspondería a una aceptación materializada, como última declaración formativa, presuponiendo una oferta.

"En consecuencia, puede definirse el contrato real como aquél que requiere para su celebración que el acuerdo de voluntades se materialice mediante la entrega del bien en que recae el contrato (...). Debe tenerse presente que en el contrato real la entrega no es la ejecución del contrato, sino uno de los dos elementos formativos de este - el otro es el consentimiento-, de tal manera que la falta de uno de ellos, cualquiera que sea, da lugar a la inexistencia del contrato" ${ }^{\prime 22}$ (el subrayado es nuestro).

Se aprecia, conforme al texto reproducido, que el maestro De la Puente sostiene, a diferencia nuestra, que el consentimiento formativo se requeriría siempre, siendo que además se necesitaría de la entrega para que recién se entienda celebrado el contrato, para que adquiera existencia.

Es la misma visión que habría tenido el legislador nacional cuando al redactar el artículo 1352 del Código Civil, al referirse a los contratos formales, señala que éstos requieren, "además" del consentimiento, la observancia de la forma señalada por ley bajo sanción de nulidad, de manera que también habría un doble requisito para fines de existencia. Consideramos que no se justifica postular un sistema de "doble requisito" para los contratos reales -y formales-, dado que el derecho define lo que se entiende por "consentimiento". En algunos casos, consentimiento será el solo acuerdo - consentimiento simple-, en otros, ello se evidenciará por una suscripción documental o por una entrega de cosa - consentimiento calificado, contratos formales y reales, respectivamente. Conforme a ello, de no observarse la exigencia del consentimiento simple o calificado, se estará por igual ante una inexistencia negocial, no hay contrato, no es que sea inválido, nulo.

Además, si asumimos el régimen del "doble requisito" entendemos que estaríamos ante un problema práctico: la legislación que regula el carácter real no sanciona con nulidad la inobservancia de la entrega. Por ejemplo, el artículo 1573 del

21. DE LA PUENTE Y LAVALLE, Manuel. Op. cit. Tomo II, pp. 22-25.

22. DE LA PUENTE Y LAVALLE, Manuel. Op. cit. Tomo I, p. 141. 
Código Civil de 1936 establecía "Por el mutuo una persona entrega a otra cierta cantidad de dinero $o$ de cosas que se consumen por el uso, con obligación de la segunda de devolver otro tanto de la misma especie y calidad"; conforme a ello, de no mediar entrega, no había consenso, no había contrato, se estaba definitivamente ante un caso de inexistencia antes que de invalidez. El sistema del "doble requisito" parte de la premisa que ya se contaría con el consentimiento, requiriéndose de algo más, y esto último puede derivar en conflictos. No tenemos duda que puede haber "consentimiento", pero en sentido coloquial, en el plano del lenguaje común, pero no en el plano del lenguaje estrictamente jurídico, porque en el marco de los contratos formales y reales, el consentimiento - y la correlativa existencia negocial- sólo se genera con la suscripción documental y con la entrega de la cosa, respectivamente.

Mientras en los contratos consensuales, ambas partes pueden declarar su voluntad, manifestando su absoluta coincidencia, de manera libre, sin necesidad de una específica forma, y mientras en los contratos formales, la forma es la voluntad misma, de manera que las partes deben declarar su respectiva voluntad de una misma y específica manera, según la forma establecida por ley bajo sanción de nulidad, tratándose de los contratos reales no se trata que ambas declaraciones radiquen en la entrega de cosas, sino que se requiere que una de las partes exteriorice su voluntad de contratar mediante la entrega de la respectiva cosa, lo cual corresponderá a su aceptación respecto de la oferta generada previamente, atendiendo a que la aceptación es la última declaración prenegocial y deriva, una vez conocida por el oferente, en el cierre formativo del negocio. Sin entrega no hay, no existe contrato, no es que el contrato sea inválido o ineficaz.

Nuestro actual Código Civil reconoce en su artículo 1352 la celebración de contratos consensuales y formales, habiéndose descartado la configuración de los reales, siendo muy sencilla la respectiva razón: la entrega de la cosa evidencia ejecución, presupone un acuerdo, no es el contrato.

Conforme analizaremos más adelante, la regla del artículo 1352 del Código Civil no sólo es im- perativa, sino que al ser estructuradora en materia de formación volitiva negocial, postulamos que es una auténtica regla de nuestro orden público contractual. La ley acepta la existencia de contratos consensuales y formales, la niega tratándose de los contratos reales.

Otro tema será si las partes, en el marco de la autonomía privada, pueden acordar un consentimiento calificado o no, esto es, si pueden someterse a una solemnidad de fuente convencional.

\section{MARCO NORMATIVO APLICABLE AL PERFECCIONAMIENTO CONTRACTUAL}

Nos interesa destacar, como marco normativo general del presente trabajo, las siguientes disposiciones de nuestro Código Civil, en materia de acto jurídico:

\section{"Artículo 143.- Cuando la ley no designe una forma específica para un acto jurídico, los interesados pueden usar la que juzguen conveniente."}

La norma en cuestión hace referencia a la denominada libertad de forma, esto es, que el agente o los agentes pueden exteriorizar su voluntad de la manera que mejor lo estimen: expresa o tácitamente. Si aplicamos esta regla general de acto jurídico a contratos, bien puede afirmarse que, salvo que la ley establezca la celebración sujeta a una determinada forma bajo sanción de nulidad, las partes pueden celebrar al contrato bajo la forma que estimen conveniente. Tanto en materia de acto jurídico como de contratos la regla es la misma: prevalece formativamente la sola voluntad, salvo que la ley establezca cosa distinta.

"Artículo 144.- Cuando la ley impone una
forma y no sanciona con nulidad su inobser-
vancia, constituye sólo un medio de prueba
de la existencia del acto." Ingresamos al campo de la forma prescrita que corresponde al concepto de formalidad-, la cual siendo de carácter documental, puede ser simplemente probatoria - relativa- o consustancial —absoluta—al acto: Formalidad 
o exigencia de forma para fines ad probationem o ad solemnitatem, respectivamente.

La forma probatoria no afecta la identidad del respectivo acto, o contrato, el mismo que seguirá siendo consensual, esto es, que la sola declaración permite la formación del respectivo acto. De haber una exigencia de forma no esencial, bien podemos referirnos a negocios consensuales relativos. Dicha subcategoría de consensualidad se opone a la de los negocios consensuales absolutos, que son aquellos en que la ley no establece una determinada forma para fines de la formación de la voluntad: irrestricta libertad de forma. Así, por ejemplo, en atención al artículo 1098 del Código Civil, el acuerdo, convenio o contrato hipotecario es un negocio consensual relativo; en cambio, conforme al artículo 1529 del Código Civil, la compraventa es un negocio consensual absoluto.

Lo establecido en el artículo 225 del Código Civil - "No debe confundirse el acto con el documento que sirve para probarlo. Puede subsistir el acto aunque el documento se declare nulo"- es consistente sistemáticamente con el artículo 144 bajo comentario. En efecto, de admitirse que una determinada forma es simplemente probatoria, la nulidad del respectivo documento - sea una sola forma escrita, con fecha cierta, o una escritura pública, que son las maneras referidas en la ley- no significará la nulidad del acto o negocio celebrado, el mismo que podrá probarse por otros medios. En ese contexto, la indicada invalidez no afectará en un ápice a la existencia negocial.

El artículo 144 del Código Civil no se opone a lo establecido en su artículo 143, ya que en ambos casos se está bajo la regla de libertad de forma, sea absoluta o relativa.

De manera complementaria, ya en el ámbito particular de contratos, interesa destacar las siguientes disposiciones de nuestro Código Civil:
"Artículo 1352.- Los contratos se perfeccionan por el consentimiento de las partes, excepto aquellos que, además, deben observar la forma señalada por la ley bajo sanción de nulidad."

Conforme a este artículo, tratándose del perfeccionamiento constitutivo de contratos, sean nominados o innominados, típicos o atípicos, se reconoce como regla general la existencia de los contratos consensuales y, como regla excepcional, de los contratos formales. Tratándose de los contratos consensuales, impera la libertad de forma; y, tratándose de los contratos formales, la declaración de voluntad se confunde con la exigencia legal de una determinada forma, la misma que a su vez está establecida bajo sanción de nulidad, generándose identidad entre la declaración de voluntad -contenido-y el correspondiente documento -continente. Conforme ya hemos referido, la exigencia que la voluntad común de las partes se exprese de una determinada forma, bajo sanción de nulidad, no debería llevarnos a asumir que en caso contrario se genera nulidad, siendo más bien que el efecto es la inexistenciaa ${ }^{23}$; conforme a ello, la referencia a una forma bajo sanción de nulidad es simplemente para que sea manifiesto que no se trata de una forma probatoria, que presuponga existencia.

Los contratos consensuales pueden ser absolutos o relativos; los primeros carecen en su regulación de la indicación de cualquier forma con relación a su celebración, por lo que ello queda sujeto a lo que estimen irrestrictamente las partes; los segundos, están sujetos a una forma, pero sin que su inobservancia sea sancionada con nulidad, tratándose de una simple forma probatoria, por lo que el contenido no se identifica necesariamente con el continente. En oposición, los contratos formales están sujetos a una solemnidad, declaración y forma - cuya inobservancia se sanciona con nulidad- se confunden, se identifican; de no observarse la forma legal establecida, se generaría nulidad, aunque

23. DE LA PUENTE Y LAVALLE, Manuel. Op. cit. Tomo II, p. 144. 
reiteramos que, en rigor, antes que invalidez es inexistencia, ya que para el ordenamiento no se habría generado acuerdo volitivo alguno.

Si nos remitimos a los artículos 140 , inciso 4 , y 219, incisos 1 y 6, del Código Civil se aprecia una redacción concordante con el artículo 1352 bajo comentario general, ya que se separa lo relativo a la manifestación - declaración- de voluntad de la observancia de la forma prescrita bajo sanción de nulidad. En términos latos ello es correcto; el tema radica en evaluar si resulta sostenible afirmar que el acto, el contrato, es nulo por inobservancia de forma solemne. ¿No es que la forma solemne es esencial?, ¿sin la observancia de la forma esencial debe entenderse que la declaración existe, pero que no despliega efectos?, ¿o es que debe asumirse que simplemente no hay declaración, que no hay acuerdo de voluntades en materia contractual?

Postulamos que, en términos estrictos, la declaración de voluntad, el consentimiento, en algunos casos - contratos formales o sujetos a solemnidad - sólo se genera de observarse la forma esencial — sancionada con nulidad, para diferenciarla en el texto legislativo de la que es simplemente probatoria. De no acatarse dicha forma, la voluntad no ha sido declarada para la ley, por lo que no se constituye el acuerdo de voluntades: inexistencia contractual.

Admitir lo contrario, implicaría admitir indirectamente situaciones que estimamos inaceptables. Por ejemplo, de acuerdo al artículo 2001, inciso 1, del Código Civil, la acción de nulidad prescribe a los diez años. La inexistencia, que es la ausencia de negocio, no produce, no puede producir, efecto alguno, siendo imprescriptible ${ }^{24}$, por lo que siempre podrá invocarse que no se generó contrato alguno porque no se alcanzó o logró jurídicamente el consentimiento, no es que éste se logró y quedó "pendiente" satisfacer el -segundo- requisito de suscribir un documento como forma solemne.
Lo que regula el artículo 1352 del Código Civil es ciertamente el perfeccionamiento constitutivo contractual: Todo contrato demanda de consenso o consentimiento, el cual puede ser simple o calificado. El simple significa que la declaración volitiva puede expresarse de la manera que mejor lo estimen los interesados. El calificado corresponde a una suerte de ficción jurídica: el "consentimiento" que ya se habría producido en los hechos no es tal para el derecho, el consentimiento sólo se verificará jurídicamente en la medida que los interesados se expresen de la forma documental que establece imperativamente la ley, forma que es identificada porque es regulada bajo sanción de nulidad; si no lo hacen, el pretendido negocio será inexistente, porque la voluntad común para ser reconocida debe ser exteriorizada necesariamente de cierta forma, y no de otra.

Insistimos en la tesis ya expresada. La referencia normativa a la forma exigida bajo sanción de nulidad, no implica que en caso de inobservancia el respectivo negocio sea inválido, sino que se trata de una referencia a determinada forma para distinguirla, para excluirla, respecto a cualquier otra forma que pudiese ser exigida pero sólo con carácter probatorio. Lo fundamental es que la inobservancia de la forma solemne significará que para el ordenamiento no se ha generado consentimiento, el que se habría formado en los hechos carece simplemente de relevancia o significado formativo.

Para finalizar, como bien sabemos, en materia jurídica hay muchos desencuentros que pueden ser más aparentes que sustanciales. La clasificación formativa propuesta de contratos consensuales y formales, podría también enunciarse como de contratos consensuales y solemnes, previa mención que existe un rubro de contratos formales, sólo que la forma de estos últimos puede ser probatoria o sustancial; si se trata de una forma únicamente probatoria, el contrato será siempre consensual; pero si se trata de una forma esencial, el contrato será solemne. Es cuestión de palabras, no de conceptos. 
"Artículo 1411.- Se presume que la forma que las partes convienen adoptar anticipadamente y por escrito es requisito indispensable para la validez del acto, bajo sanción de nulidad."

Esta norma no tiene antecedentes en nuestra legislación civil. Si nos quedamos en el plano meramente literal, de alguna manera legitimaría a las denominadas solemnidades convencionales, esto es, a las formalidades necesarias establecidas por las propias partes contratantes, y no por la ley. Para fines de asociar esta norma - de carácter contractual - con las precedentemente enunciadas, debemos considerar que la categoría de actos jurídicos solemnes - sujetos a una forma ad solemnitatem - corresponde a la clasificación de los contratos formales -en cuanto a su perfeccionamiento constitutivo-, por lo que estos últimos podrían ser tanto de fuente legal como convencional.

Ante dicha lectura resultaría válido cuestionarse si la noción de autonomía privada — que sustenta al moderno derecho contractual-es tan amplia que permita o tolere que las partes - que carecen por sí mismas de un rol normativo, dado que el mismo les es delegado por el ordenamiento- pueden convenir requisitos de validez, causales de nulidad. Debe tenerse presente que, según ya ha sido referido precedentemente, en materia de nulidad —más allá que sea absoluta o relativa - se está bajo el principio de reserva legal. Conforme se desarrollará, para intentar desentrañar los alcances de la norma, y estructurar una respuesta al cuestionamiento propuesto, resultará necesario partir de una premisa: todo contrato es una autorregulación de intereses, por lo que debería asumirse que las partes bien pueden definir cuándo sus declaraciones implican que quedan comprometidas, y con qué alcances, siendo además necesario recurrir a las nociones de inexistencia e invalidez negocial. Ellas harán las veces de estrella polar, nos ayudarán para llegar a puerto, o para representarnos que hemos llegado a buen puerto.

"Artículo 1412.- Si por mandato de la ley o por convenio debe otorgarse escritura pública o cumplirse otro requisito que no revista la forma solemne prescrita legalmente o la con- venida por las partes por escrito bajo sanción de nulidad, estas pueden compelerse recíprocamente a llenar la formalidad requerida.

La pretensión se tramita como proceso sumarísimo, salvo que el título de cuya formalidad se trata tenga la calidad de ejecutivo, en cuyo caso se sigue el trámite del proceso correspondiente".

Interesa en particular el primer párrafo de la norma reproducida, conforme al cual la posibilidad de compelerse recíprocamente el cumplimiento de una forma sólo es posible tratándose de aquellos contratos en que la forma no se identifica constitutivamente con la declaración de voluntad, esto es, procede tratándose de los contratos consensuales y que estén sujetos, a su vez, a una formalidad de carácter ad probationem -contratos consensuales relativos. Ofendería gravemente a la autonomía privada, significaría prescindir de la libertad de contratar, si es que se admitiese que, tratándose de los contratos formales -en los que forma solemne y consentimiento se identifican-, resulta posible compeler el cumplimiento de la respectiva forma, prescrita bajo sanción de nulidad, ya que ello implicaría en los hechos obligar a contratar.

Pero el primer párrafo también llama la atención porque excluye de la exigencia de forma probatoria a aquellos contratos sujetos a solemnidad, sea ésta dispuesta legalmente o por acuerdo; lo cual legitima a sostener que habría una representación legislativa en el sentido que las partes gozan de libertad para regular el tema de la formación del consentimiento, sobreentendiéndose que el ejercicio de dicho poder negocial no debe contravenir normas imperativas.

"Artículo 1413.- Las modificaciones del contrato original deben efectuarse en la forma prescrita para ese contrato".

Por último, este artículo, que tantas veces se invoca en la práctica, está relacionado a la forma que debe observarse en el escenario de modificaciones contractuales, correspondiendo determinar si su aplicabilidad se limita a los contratos formales o, si puede hacerse extensiva inclusive 
a los consensuales, sujetos a determinada forma ad probationem.

En función a las normas legales transcritas, se generan -al menos - tres grandes inquietudes sobre las que pretendemos reflexionar en el presente trabajo: Primera, ¿pueden las partes, en el marco de la autonomía privada, convenir un perfeccionamiento constitutivo real, obviando - de existir - la tipificación del respectivo negocio como consensual o formal? Segunda, ¿pueden las partes, sobre la base de la autonomía privada, acordar que un contrato consensual, sea absoluto o relativo, adquiera carácter formal?, ¿cómo entender entonces los alcances del artículo 1411 del Código Civil de 1984, así como de su artículo 1412? Y tercera, ¿pueden las partes, siempre bajo el régimen de la autonomía privada, modificar un contrato siguiendo una forma distinta a la prescrita para fines de su celebración, cuando la inobservancia de la misma no está sancionada con nulidad?

Si al responder dichas interrogantes se advierte que se está frente a un problema de regulación legislativa, se justificaría definitivamente una modificación de las normas pertinentes del actual Código Civil, teniendo en consideración que las normas deben presentar, en la medida de lo posible, el tenor más preciso para evitar interpretaciones que desnaturalicen sus alcances, máxime cuando muchas veces nos sentimos tentados a asumir interpretaciones literales, textuales antes que contextuales. En otros casos, por más que se advierta que la redacción de la respectiva norma legal no es la más feliz, puede ser que se concluya que el problema no es de tal magnitud que justifique una modificación legislativa, posición que implica un voto de confianza implícito en que los operadores jurídicos posean criterio suficiente para aplicar correctamente el texto legal que pudiese ser controvertido, máxime cuando el problema puede ser apasionante académicamente pero de escasa trascendencia al no conocerse de jurisprudencia significativa.

\section{PACTO SOBRE PERFECCIONAMIENTO CONSTITUTIVO REAL}

Un contrato no sólo es un acuerdo de voluntades de contenido patrimonial de naturaleza obligacional, sino que - atendiendo a su trascendencia para fines del tráfico- el mismo es objeto de regulación legislativa, tanto en lo que se refiere a su formación como a su extinción. La ley es la que define, o tolera, cuándo se genera el válido acuerdo de voluntades, siendo también la que establece la manera en que se extingue la correspondiente relación jurídica, regulando por ejemplo lo relativo a la resolución como remedio específico cuando se materializa el riesgo natural que se asume al contratar, esto es, cuando se verifica el incumplimiento, siendo que en ese contexto la resolución sólo se podrá generar de seguirse uno de los tres procedimientos regulados legislativamente, siendo su nota común la necesidad que el acreedor o parte fiel comunique al deudor o parte infiel su pérdida de interés en mantener el vínculo.

Atendiendo a lo anterior, cabe cuestionarse sí, en autonomía privada, en ejercicio de su poder negocial reconocido por el ordenamiento, las partes pueden convenir que el contrato a celebrar será real, esto es, que solo se entenderá celebrado en la medida que la cosa sobre el cual recae sea efectivamente entregada, identificándose consentimiento con entrega.

Adviértase que, en rigor, al ser la entrega un asunto de ejecución contractual, que presupone un título o negocio que justifique dicha entrega, ante la falta de esta última correspondería que la parte fiel del contrato resuelva por incumplimiento, derivándose de ello los efectos propios de toda resolución: liberatorio, reintegrativo y reparatorio, lo cual implica que la parte fiel tendría que evidenciar que, ejerciendo el correspondiente derecho potestativo, opta por la extinción del contrato, por lo que mientras ello no ocurra, el contrato seguiría vigente por más que hubiese una afectación al interés del acreedor.

Lo primero a considerar es si existe prohibición legal para lo que se pretende. La respuesta - preliminarmente aparente- es negativa. El artículo 1352 del Código Civil regula el perfeccionamiento constitutivo señalando que los contratos son consensuales, salvo que sean

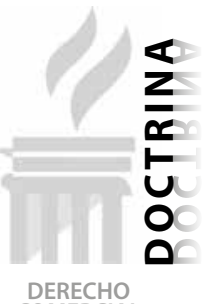

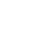


formales, pero omite referirse a los contratos reales, por lo que no prohíbe expresamente su celebración. Siendo que resultaría lícito realizar todo aquello que no está prohibido, nada impediría que las partes pudieran entonces convenir el carácter real en la formación del contrato.

Tomemos el ejemplo de una compraventa, el cual es el contrato consensual por excelencia, consensual absoluto ya que la ley no lo asocia con una determinada forma. De convenirse durante la negociación el carácter real del contrato, las partes se estarían representando que sólo de mediar la efectiva entrega del bien se habría celebrado el contrato. De no mediar entrega, el vínculo no se habría formado y, por consiguiente, no serían exigibles las respectivas obligaciones. La ventaja del pacto radicaría en que se evitaría la asunción del riesgo de un eventual incumplimiento por el vendedor, siendo que el precio sería pagado por el comprador sobre la base de haberse recibido ciertamente el bien y generado - con ello- el vínculo que permite concluir que el pago del precio es debido. No se generaría la actual disociación entre comprador y propietario; bajo un esquema de celebración real, el comprador - como regla general- sería propietario por el sólo mérito de haber recibido el bien, pudiendo oponer su derecho al menos desde la perspectiva del modo posesorio. De hecho, por el pacto formativo real se estaría modificando el tipo de la compraventa - artículo 1529 del Código Civil: "Por la compraventa el vendedor se obliga a transferir la propiedad de un bien al comprador y este a pagar su precio en dinero"- ya que este pasaría a ser uno conforme al cual "Por la compraventa el vendedor entrega el bien y, salvo pacto distinto, transfiere su propiedad al comprador, quien se obliga a pagar su precio en dinero".

Asimismo, tomemos el ejemplo de una donación inmobiliaria. Sin perjuicio de observar la exigencia legal de celebración mediante escritura pública - artículo 1625 del Código Civil de 1984-, en el marco de la autonomía privada, las partes convendrían que la donación además sólo se entendería celebrada de haber mediado, por parte del pretendido donante, la entrega del respectivo inmueble. Las partes convienen, por así denominarlo, un segundo requisito de validez, pactan más allá de lo que la ley demanda. En el ejemplo propuesto se parte de la premisa que "sin perjuicio" de observarse la correspondiente solemnidad, porque se entendería que al provenir de una exigencia imperativa, no podría enervarse su cumplimiento. El tema es que las partes estarían pactando más allá de la norma imperativa, interpretándola como si regulase una exigencia mínima.

Conforme se aprecia, el carácter real neutralizaría de manera absoluta la aversión al riesgo del acreedor de la respectiva cosa, porque de no recibirla, no se habría celebrado contrato alguno. Tratándose del caso específico de la compraventa, a través de este pacto dicho acreedor se evita invocar una resolución por incumplimiento, ya que al no haber celebrado contrato alguno, no tiene precio que pagar, no hay necesidad de generar una declaración sobre pérdida de interés que justifique la extinción del contrato. Tratándose de la donación, si bien la resolución será inviable jurídicamente por tratarse de un contrato unilateral, el pacto permitiría que el donatario adquiera del bien mismo y no un crédito con relación a aquél, cuyo cumplimiento por el donante sea contingente.

Sin embargo, estimamos que no son jurídicamente viables los pactos propuestos.

Si bien no está prohibida expresamente la celebración de contratos reales, ello se deriva implícitamente del propio enunciado del artículo 1352 del Código Civil vigente. Si bien en doctrina - y en legislación comparada- se admite que los contratos pueden celebrarse como consensuales, formales y reales, la ley nacional sanciona que los contratos son consensuales, salvo que sean formales, de manera que resulta evidente - a nuestro juicio- que la formación real ha quedado proscrita, por lo que está implícitamente prohibida, ya que la regla general formativa - contratos consensuales - sólo admite una excepción - contratos formales-.

Bien podemos afirmar que del propio tenor del artículo 1352 del Código Civil no se reconoce a los contratos reales, porque la entrega del bien 
no corresponde a un tema de celebración sino de ejecución contractual, lo que presupone la previa y válida celebración de un acuerdo de voluntades de carácter contractual. La posición del legislador peruano ha sido clarísima en este tema, es así que Arias Schreiber ${ }^{25}$ manifiesta, en su emblemática obra Exégesis, que en materia formativa de contratos:

"Se ha dado, pues un paso trascendental al implantarse el sistema de la consensualidad, eliminando la entrega o tradición, como regla general. El acto de la entrega debe entender$\underline{\text { se, en consecuencia, no como un elemento }}$ constitutivo o formal sino como parte del mecanismo en el cumplimiento de lo prometido" (el subrayado es nuestro).

Siendo que la referencia del autor a un "elemento constitutivo o formal" lo entendemos como "elemento constitutivo o formativo", ya que lo formal es estrictamente documental. De la misma manera, De la Puente ${ }^{26}$ no sólo suscribe una posición acorde con la supresión de los contratos reales, sino que además considera que ello facilita la contratación moderna, evitando inclusive la necesidad de celebrar un doble acuerdo para un mismo negocio: contrato consensual preparatorio y contrato definitivo real.
¿Por qué tiene relevancia citar a ambos autores nacionales? Porque el actual tenor del artículo 1352 del Código Civil no sufrió prácticamente modificaciones relevantes en el largo proceso de elaboración de este último, durante los casi veinte años que duró el proceso, tanto bajo la denominada "Comisión Reformadora"27 como bajo la "Comisión Revisora"28. La nota común fue regular un perfeccionamiento constitutivo sujeto a la consensualidad, salvo que aplicase la solemnidad.

Además, no debe olvidarse el fundamento del artículo 1352 en cuestión atendiendo a su antecedente legislativo: Código Civil de 1936, en el cual se admitía que los contratos podían ser regulados como consensuales, formales y reales, como era, por ejemplo, el caso del mutuo, tratándose de los contratos reales. El legislador de 1984 estimó que el tema de la entrega de la cosa sobre la cual recae el acuerdo negocial no es un tema de celebración sino de ejecución, presupone un contrato. Por lo tanto, resultaría inconsistente que la voluntad del particular prevalezca frente a la del legislador. Resultaría absurdo que mediando una proscripción de formación real, se admitiese que las partes pueden convenir un contrato real. Las partes no pueden ir más allá del límite legal, no pueden traspasar

25. ARIAS SCHREIBER, Max. “Exégesis". Tomo I. Lima: Gaceta Jurídica Editores, p. 101.

26. DE LA PUENTE Y LAVALLE, Manuel. Op. cit. Tomo I, p. 144.

27. La "Comisión Reformadora" fue creada mediante Decreto Supremo 95 del 1 de marzo de 1965, expedido durante el primer gobierno constitucional del presidente Fernando Belaúnde. A los miembros de dicha comisión se les encargó el estudio y revisión del Código Civil de 1936, esto es, cuando el mismo no había cumplido ni siquiera treinta años de vigencia. Entre sus miembros más renombrados tenemos, en un primer momento, a Carlos Fernández Sessarego, José León Barandiarán, Rómulo Lanatta Güilhem, Héctor Cornejo Chávez y Max AriasSchreiber Pezet, siendo que de manera posterior se integran Felipe Osterling Parodi, Jorge Avendaño Valdez, Lucrecia Maisch Von Humboldt, Manuel de la Puente y Lavalle y Fernando de Trazegnies Granda, entre otros. Si bien el encargo inicial fue proponer modificaciones al Código Civil de 1936, sus miembros optaron finalmente por elaborar y proponer un texto sustitutorio, un nuevo código civil. Los trabajos de esta comisión se extenderán hasta 1981, cuando se presenta al Poder Ejecutivo — segundo gobierno constitucional del presidente Fernando Belaúnde- el respectivo proyecto, que bien puede ser denominado como "primer proyecto".

28. La "Comisión Revisora" fue creada por Ley 23403, promulgada en mayo de 1982, y tenía precisamente por objeto revisar el denominado primer proyecto o proyecto elaborado por la "Comisión Reformadora". Entre sus miembros más destacados figuraban Javier Alva Orlandini, Roberto Ramírez del Villar, César Fernández Arce y Jack Bigio Chrem. Su competencia fue complementada mediante Ley 23756, promulgada en diciembre de 1983 . Los trabajos de esta comisión se extenderán hasta julio de 1984, cuando se presenta al Poder Ejecutivo el respectivo proyecto — que bien puede ser llamado como"segundo proyecto", elaborado sobre la base del primer proyecto-, el mismo que será finalmente promulgado como ley de la república. 
las fronteras del poder negocial que les ha sido reconocido. La regla es non plus ultra, no que puedan actuar plus ultra.

De otro lado, el artículo 1352 del Código Civil de 1984 no es una norma de naturaleza supletoria, sujeta en su aplicación a lo que estimen las partes, sino que se trata de una norma imperativa en sentido lato, interesando inclusive a nuestro orden público contractual: los contratos quedan celebrados por el mérito del solo consenso, salvo aquellos en que dicho consenso debe evidenciarse satisfaciendo la correspondiente exigencia documental, enunciada bajo sanción de nulidad. Hay reserva legal, dentro de dichos márgenes, sobre la manera de formar los contratos; en consecuencia, atendiendo a los márgenes de maniobra que poseen las partes para ejercer su autonomía privada, entendemos que las modalidades de perfeccionamiento formativo no son una materia que haya quedado sometida al criterio irrestricto de las partes.

No obstante lo anterior, causa extrañeza lo expresado por DE LA PUENTE ${ }^{29}$ al realizar sus comentarios al artículo 1352 del Código Civil de 1984:

"Debo hacer una consideración final. La supresión de la categoría de los contratos reales no significa que no sea posible celebrarlos como contratos atípicos, pues muchas veces resultará conveniente que la entrega del bien se haga en el momento de celebrar el contrato consensual, para que quede evidencia de ella y justifique el derecho a la restitución".

Y causa extrañeza, por distintas razones. La primera de ellas se relaciona al sustento de por qué la categoría de los contratos reales fue suprimida en 1984, dado que se asumió que la entrega de un bien presupone un título, un acuerdo, un contrato ya celebrado, más allá de la oportunidad en que se verifique la respectiva entrega, sea inmediata o diferida. Conforme a ello, no resultaría consistente proscribir el carácter real tratándose de los contratos típicos, pero permitirlo en materia de contratación atípica, de manera especial tratándose de contratos innominados; y no resultaría consistente porque en dichos casos se estaría postulando que, sujeto a la voluntad de las partes, la entrega puede identificarse con el consentimiento mismo, y no que la entrega presupone consentimiento.

De otro lado, la propuesta misma del maestro carece, desde nuestra perspectiva, de una orientación concluyente. Nada impide que en el marco de un contrato consensual - referido por De la Puente - o formal, la entrega sea inmediata; es más, esa es la regla atendiendo al principio de oportunidad del pago. Desde el momento en que puede acreditarse la entrega, de extinguirse el vínculo contractual, corresponderá la restitución.

Por último, siendo que el artículo 1353 del Código Civil vigente establece que las reglas generales sobre contratación previstas en la Sección Primera del Libro VII —Fuentes de las Obligaciones- del Código Civil se aplican a todos los contratos de derecho privado, inclusive a los innominados -entendiéndose por tales a los atípicos, conforme a la terminología empleada en la redacción del Código Civil de 1984, lo cual comprende tanto a los contratos nominados no tipificados legislativamente como a los innominados-, y siendo que de acuerdo a dichas reglas el perfeccionamiento constitutivo contractual es, en principio, consensual, salvo que sea formal, habiéndose suprimido el perfeccionamiento real, no resulta aceptable postular que en autonomía privada las partes puedan regular un perfeccionamiento constitutivo diferente, por más que el respectivo negocio no se encuentre tipificado.

Somos de la opinión que el artículo 1352 del Código Civil de 1984, así como lo es también su artículo 1374, o su artículo 1363, entre otros, corresponden a reglas que interesan a nuestro orden público contractual y, por consiguiente, son reglas imperativas, inderogables.

29. DE LA PUENTE Y LAVALLE, Manuel. Op. cit, p. 145. 
En síntesis, no resulta aceptable, bajo un concepto malentendido de autonomía privada irrestricta, postular que las partes puedan acordar el carácter formativo real para un contrato consensual, menos para uno que se encuentra regulado como formal, ya que esto proviene de norma imperativa. Las partes pueden acordar subordinar la eficacia del negocio - ya celebrado- a la entrega, pero no pueden subordinar su existencia.

\section{PACTO SOBRE PERFECCIONAMIENTO CONSTITUTIVO FORMAL O SOLEMNIDAD CONVENCIONAL}

Hemos señalado precedentemente que el artículo 1411 del Código Civil no tiene antecedente en nuestra legislación, siendo que el legislador de 1984 tomó la fórmula legislativa italiana $y$, desde su propia perspectiva, la complementó, señalando que la forma en cuestión es un requisito de validez, "bajo sanción de nulidad".

¿Pueden las partes pactar expresamente una solemnidad para la formación del consentimiento, de manera que identifican necesariamente voluntad común con forma documental?, ¿ello implica que las partes regulen lo relativo a la validez del negocio, ya que establecerán que deben observar cierta forma "bajo sanción de nulidad"? La norma bajo comentario puede generar diversas aproximaciones interpretativas, de allí la conveniencia de delimitar sus alcances.

El artículo 1352 -Formas convencionales- del Código Civil italiano de 1942 establece lo siguiente:

"Si las partes han convenido por escrito que adoptarán una determinada forma para la celebración futura de un contrato, se presume que la forma se establece para la validez del mismo" (el subrayado es nuestro).

En nuestro medio, el artículo 1431 del primer proyecto del actual Código Civil, elaborado por la Comisión Reformadora, disponía lo siguiente:

"Si las partes hubieran convenido por escrito adoptar determinada forma para la futura celebración de un contrato, se presume que dicha forma ha sido querida para la validez del acto" (el subrayado es nuestro).

Conforme se aprecia, la Comisión Reformadora se limitó a reproducir, palabras más, palabras menos, el texto del Codice.

Por su parte, el artículo 1376 del segundo proyecto del actual Código Civil, elaborado por la Comisión Revisora, disponía lo siguiente:

"Se presume que la forma que las partes convienen adoptar anticipadamente y por escrito es requisito indispensable para la validez del acto, bajo sanción de nulidad" (el subrayado es nuestro).

El último texto reproducido es lo que se convertirá finalmente en ley de la República.

Al realizar un sumario recorrido por los antecedentes del artículo 1411 del Código Civil de 1984 se aprecia que la Comisión Revisora habría superado la propuesta de la Comisión Reformadora, añadiendo al respectivo texto la referencia final a la "sanción de nulidad". Sin embargo, si se revisa el proyecto elaborado por la Comisión Reformadora, uno puede encontrarse que esa referencia ya había sido prevista de una u otra manera.

Así, el artículo 1388 del primer proyecto disponía lo siguiente:

"Son requisitos del contrato:

El consentimiento de las partes;

1) La causa;

2) El objeto; $y$

3) La forma, cuando resultare prescrita por la ley bajo sanción de nulidad o haya sido convenida para la futura celebración del contrato" (el subrayado es nuestro).

De otro lado, el artículo 1432 del primer proyecto disponía lo siguiente, tratándose de la forma del contrato:

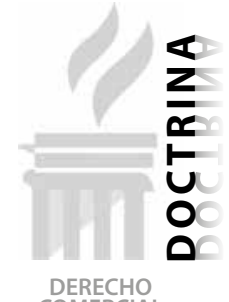

COMERCIAL 
"Si por razones de conveniencia o por mandato de la ley debe otorgarse escritura pública ocumplirse otro requisito que no revista la formalidad a que se refiere el inciso 4) del artículo 1388, las partes que han celebrado el contrato pueden compelerse recíprocamente a llenar la formalidad requerida" (el subrayado es nuestro).

Conforme a este artículo del proyecto de la Comisión Reformadora, al señalarse - por remisión legislativa - que la observancia de la forma no puede ser exigida cuando proviene de una prescripción legal bajo sanción de nulidad o que hubiera sido acordada para fines de la celebración del contrato, se está admitiendo que la solemnidad puede ser de fuente legal o convencional.

Se puede apreciar, por lo tanto, que el concepto de perfeccionamiento constitutivo formal de fuente convencional no era ajeno al criterio de la Comisión Reformadora, la que se habría representado que la solemnidad formativa del contrato podía ser tanto de fuente legal como de fuente convencional. Si bien el artículo 1388 del primer proyecto no fue considerado en el Código Civil vigente, lo cierto es que el artículo 1432 del primer proyecto sí fue recogido, correspondiendo en gran medida al actual artículo 1412 del Código Civil de 1984.

Conforme a ello, cuando la Comisión Revisora establece -en el artículo 1376 del segundo proyecto- una presunción de solemnidad contractual, dado que opera "(...) para la validez del acto, bajo sanción de nulidad", si bien pareciera que fue más allá de lo que se habría representado la Comisión Reformadora en el artículo 1431 del primer proyecto - "(...) dicha forma ha sido querida para la validez del acto"en realidad no fue así, porque el añadido de "bajo sanción de nulidad" era consistente con lo propuesto por la Comisión Reformadora, ya que en varios artículos del primer proyecto -entre ellos, los artículos 1388 y 1432- se evidencia la representación que, bajo la autonomía privada, era posible que las partes condicionasen la celebración del contrato al cumplimiento de una solemnidad, a la observancia de una forma necesaria, entendiéndose por tal a la forma bajo sanción de nulidad, no a la forma probatoria.
Lo que sería cuestionable es que, en el entendimiento legislativo, la formación del contrato estaría sujeta a un régimen de "doble requisito", ya que se requeriría tanto de consentimiento como de observancia de forma solemne, sin perjuicio que el texto invitaría a sostener que la ley legitimaría a las partes para convenir solemnidades, esto es, declaraciones expresas, escritas —más allá de su graduación-, bajo sanción de nulidad, de manera que en razón de esto último ellas terminarían definiendo lo que es válido o no, con lo cual el principio de reserva legal en materia de nulidad quedaría deshecho.

La norma nacional no debería ser entendida desde dicha perspectiva.

No debe olvidarse que un concepto es la existencia - e inexistencia-y otro lo relativo a la validez - o invalidez. En el marco de la autorregulación de intereses no tenemos duda que las partes pueden definir cuándo se entiende celebrado un contrato, cuándo se alcanza o logra el consentimiento - sujeto a ciertas limitaciones, dado que los pactos no pueden contrariar, en general, a las reglas imperativas-, pero en función a la reserva legal en materia de nulidad, las partes carecen de competencia para regular la validez, para establecer lo que es nulo o anulable.

Una sola precisión adicional. Las partes pueden definir cuándo se entiende celebrado el contrato, cuándo se entiende formado el consentimiento, pero dentro de los márgenes de maniobra dispensados por el ordenamiento: contratación consensual o contratación formal, más no contratación real.

El artículo 1352 del Codice, al regular la forma contractual, establece una presunción de observancia de la forma convencional para la "validez" del contrato, siendo que en dicho código no se aprecian normas semejantes a lo establecido en los artículos 1388 y 1432 del primer proyecto en cuanto a las pretendidas solemnidades convencionales. Es más, el artículo 1325 del Codice, que regula los requisitos del contrato - y que habría servido de antecedente para el artículo 1388 del primer proyecto de nuestro Código Civil-, establece lo siguiente: 
“Los requisitos del contrato son:

1) El acuerdo de las partes;

2) La causa;

3) El objeto; $y$

4) La forma, cuando resulta prescrita porla ley bajo sanción de nulidad" (el subrayado es nuestro).

No figura una sola palabra o referencia a la posibilidad que la forma esencial pueda provenir del pacto, de la autonomía privada; empero, la cuestión radica si puede afirmarse jurídicamente que las partes están impedidas de subordinar el nacimiento del consenso a la observancia de una forma solemne, porque así convenga a su interés en particular. Postulamos una respuesta negativa, no hay impedimento.

El término"validez" — mencionado en el artículo 1352 del Código Civil italiano, antecedente del artículo 1411 de nuestro Código Civil-es polisémico, por lo que se abre un abanico de interpretaciones sobre los efectivos alcances del artículo bajo comentario.

Comentando los alcances de la norma italiana, $\mathrm{ROPPO}^{30}$ expresa lo siguiente, que merece ponerle atención:

"El vínculo de forma puede derivar, en lugar de la ley, de la autonomía privada. En primer lugar, de un ejercicio unilateral de autonomía privada: el oferente puede ex artículo 1326, vincular la eficacia de la aceptación al uso de una forma determinada. Pero también de su ejercicio consensual, y esto es, de un pacto sobre la forma: las partes pueden convenir "adoptar una determinada forma para la futura celebración de un contrato" - artículo 1352-.

El problema central del pacto sobre la forma se refiere a las consecuencias de su violación:
¿Cuál es el régimen del contrato sucesivamente estipulado en forma diferente de la pactada? Primeramente, manda la voluntad de las partes. Estas pueden haber convenido que la forma pactada — por ejemplo, la escrituratrascienda en el terreno de la prueba: en tal caso, el futuro contrato no podrá probarse por testigos, sino solo en vía documental. (...) O bien pueden haber convenido que la forma transcienda en el plano sustancial y sea constitutiva de los efectos contractuales: y entonces el defecto de forma impedirá la producción de los efectos.

Si la voluntad de las partes consta, no surge problema - en particular no surge problema respecto a la admisibilidad de un pacto sobre la forma que sea en realidad un pacto sobre la prueba,-y más precisamente limitativo de los medios de prueba; esta es materia en línea de principio disponible, como confirma el artículo 1469-bis, inciso 18. Surgen problemas cuando las partes pactan una forma, sin decir a que fin. En tal caso es necesario distinguir según que el pacto sobre la forma haya sido celebrado por escrito, o no.

Si el pacto reviste forma escrita, "se presume" que la forma pactada "haya sido deseada para la validez" del futuro contrato - artículo 1352-.

Al respecto, se plantean dos problemas. El primero se refiere a las consecuencias de la violación, y por consiguiente al sentido a atribuir al término "validez". Gran parte de la doctrina rechaza tomarlo al pie de la letra, negando que el contrato celebrado sin la forma pactada sea nulo tout court, y prefiriendo calificarlo, de caso en caso, solo como relativamente nulo, o como ineficaz, o incluso como no celebrado. Por su parte, la jurisprudencia muestra un comportamiento esquizofrénico: por un lado, da una lectura "fuerte" del pacto, deduciendo la nulidad absoluta, apreciable de oficio, del contrato no conforme; por el

30. ROPPO, Vincenzo. “El contrato". Lima: Gaceta Jurídica, 2009, pp. 242-244. 
otro, la debilita enormemente admitiendo la posibilidad de su revocación también tácita, con un comportamiento concluyente de las partes que podría consistir en el hecho mismo de (...) violarlo estipulando el futuro contrato sin la forma pacticia.

La tesis de la nulidad absoluta parece excesiva. Más razonable es la de una nulidad relativa y subsanable: cada parte puede hacer valer la nulidad del contrato no conforme, pero ningún tercero aunque interesado puede invocarla, ni el juez puede apreciarla de oficio; y las partes pueden subsanarla. Pero, en cuanto a la subsanación, es excesiva la tesis que da valor de comportamiento concluyente indicativo de la voluntad de revocar el pacto -y por consiguiente fuerza subsanante del contrato no conforme- a la mera celebración de este último: la voluntad de revocar el pacto - en cuanto contraria al contenido de un documento anteriorrequiere, en línea de principio, prueba documental, y puede ser probada por testigos solo dentro de los límites del artículo 2723; o bien la subsanación puede resultar de un comportamiento concluyente "fuerte" como la ejecución del contrato no conforme" (el subrayado es nuestro).

De acuerdo al referido autor italiano, comentando los alcances del artículo 1352 del Código Civil italiano - que corresponde al artículo 1411 de nuestro Código Civil-, el pacto sobre forma puede limitarse a una cuestión meramente probatoria, o radicar en una materia sustancial, siendo que en este último caso la jurisprudencia italiana estaría dividida en identificar la consecuencia por inobservancia de la forma: nulidad y anulabilidad, inclinándose el autor respecto a esta última.

No tenemos duda que la anulabilidad de un acto jurídico se asocia a la afectación de un interés particular, a diferencia de la nulidad que se asocia a intereses generales; el problema radicaría en cómo compatibilizar la tesis de la invalidez a título de anulabilidad con la regla de la reserva legal tratándose de las causales de invalidez, sea nulidad absoluta o relativa.
La tesis de la procedencia de la anulabilidad, con la posibilidad de una subsanación, no nos resulta convincente. La reserva legal corresponde a una regla de la cual no podemos sustraernos tan fácilmente.

Más allá que nuestro Código Civil exprese en la parte final de su artículo 1411 algo que ni siquiera fue expresado por el legislador italiano, esto es, la sanción de nulidad en caso de inobservancia de la forma, como efecto convencional, resulta cuestionable admitir que las partes pueden convenir una forma sustancial y subordinar la validez del negocio a su cumplimiento, dado que la determinación de la validez es de fuente legal.

Pero si enfocamos el tema desde la perspectiva de la existencia, la cuestión será diferente.

Si nos encontramos en un tema de formación del consentimiento, deberíamos asumir que la categoría comprometida es existencia / inexistencia antes que validez / invalidez. Conforme a ello, la ley presume que las partes pueden haber establecido que el negocio sólo se entenderá celebrado si es que declaran su voluntad de una y no de otra manera, y como se trata de una exigencia de forma, de forma necesaria, se entiende que la referencia a una forma bajo sanción de nulidad es a título de exclusión, en el sentido que no se trata de una forma probatoria. Bajo la presunción bajo comentario, la forma necesaria correspondiente debe ser bajo sanción de nulidad — formalidad ad solemnitatem - descartándose que sea bajo funcionalidad probatoria, ello fue lo que habría sido explicitado por el legislador nacional.

Y si se está bajo una presunción, que implica tomar como cierto lo que es incierto, no habría objeción alguna en que las partes acuerden previamente, de manera expresa, clara y puntual, subordinar la existencia del consentimiento, la formación de la voluntad común, a la observancia de una forma necesaria. $Y$ dado que subordinan la formación del contrato, y no sus efectos, se entiende que se estaría ante una formalidad ad solemnitatem antes que ad probationem.

Conforme a ello, las partes no regulan, ni se acogen a una regulación, de validez negocial, no 
ingresan a determinar lo que es nulo o no, sino que regulan la formación del consentimiento, la existencia o no del negocio.

Atendiendo a que el término "validez" es polisémico, si nos quedáramos en el texto legislativo italiano, podríamos asumir que la figura bajo comentario está asociada a la regulación convencional de una formalidad meramente ad probationem, de manera que la forma pactada sirva para probar o acreditar la celebración del negocio, para que despliegue efectos. Empero, siendo que el legislador nacional introdujo la precisión "bajo sanción de nulidad", queda descartada la forma probatoria, quedando en el ámbito de la solemnidad, asociada —en las circunstancias- a la existencia del negocio.

Insistimos, la gravedad de la reserva legal en materia de invalidez no permite sostener que la inobservancia de la forma deriva en nulidad, por lo que dicha inobservancia derivará en una presunción de inexistencia o de ineficacia, salvo que las propias partes se hubiesen representado oportunamente cosa distinta y puedan demostrarlo.

Sin perjuicio de lo expresado, debe considerarse que el Código Civil refiere el término validez, válido, como sinónimo de generación de efectos, de manera que el acto tiene valor, adquiere efectos.

Es el caso del artículo 1669 del Código Civil, conforme al cual "El copropietario de un bien indiviso no puede arrendarlo sin consentimiento de los demás partícipes. Sin embargo, si lo hace, el arrendamiento es válido si los demás copropietarios lo ratifican expresa o tácitamente".

Hay, al menos, dos posibles lecturas sobre sus alcances. La primera de ellas, nutrida esencialmente de la literalidad, implica que en caso el copropietario de un bien indiviso lo entregue en arrendamiento, sin contar con el asentimiento de los demás copropietarios, el contrato celebrado es inválido. Por consiguiente, para que el contrato sea válido se requiere que todos los demás copropietarios expresen su consentimiento. Una segunda lectura, va más allá de la literalidad, y postula que no estamos ante un tema de invalidez sino de ineficacia; por consiguiente, el contrato celebrado es válido y eficaz entre las partes materiales comprometidas, esto es, de un lado, el copropietario celebrante - que ha preterido a los demás copropietarios-, como arrendador y, de otro lado, el arrendatario; empero, se trata de un contrato ajeno o inoponible frente a los demás copropietarios, quienes asumen per se la condición de terceros, ya que no están comprometidos con la celebración del contrato, no la han asentido.

En función de su interés - propiedad indivisarespecto del bien arrendado, en caso los copropietarios preteridos expresen su asentimiento al arrendamiento ya celebrado, se entiende que dejarán de ser terceros y adquirirán la condición de parte material como arrendadores; de no manifestarse dicho consentimiento, el contrato celebrado subsiste - y vincula a quienes lo celebraron, surtiendo efectos entre ellos- pero puede afectarse su eficacia porque su celebración ha entrañado un acto que afecta a los copropietarios no participantes, quienes pueden demandar el desalojo, ya que para ellos el arrendatario carece de un título justificante de la posesión que le hubiese sido entregada por el copropietario arrendador. Por consiguiente, el uso de las categorías de contrato válido o inválido no son enfocadas finalmente desde una perspectiva de negocio jurídico, sino en un sentido menos riguroso: el contrato tiene o no valor, significado, efectos, tratándose -en el ejemplo propuesto- de aquellos que no han declarado voluntad.

A mayor abundamiento, el artículo referido indica que los copropietarios preteridos, que son jurídicamente terceros, pueden ratificar el negocio ajeno, con lo cual adquieren la condición de parte material del respectivo contrato. En materia de acto jurídico se ratifica un acto válido, de manera que pueda surtir efectos respecto de quien lo ratifica - por consiguiente, antes era un acto que le resultaba inoponible o ineficaz. El artículo 1669 del Código Civil, al referirse a la necesidad de una ratificación, está implícitamente destacando que el contrato celebrado por uno de los copropietarios del bien indiviso, con preterición de los demás copropietarios, es válido pero ineficaz tratándose de estos últimos, salvo ratificación —consentimiento- de estos últimos.

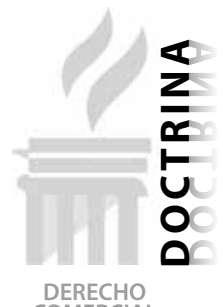


La ausencia de dicho consentimiento no encuadra en las causales de nulidad o anulabilidad establecidas en el Código Civil, siendo que no hay nulidad - absoluta o relativa-sine lege.

Retomando lo ya expresado, hay un conjunto de normas contenidas en el Código Civil vigente que pueden releerse en el sentido expuesto, esto es, leyendo como eficacia - o ineficacialo que está enunciado como validez -o invalidez. El artículo 1099 es otro ejemplo, en línea a lo señalado tratándose del artículo 1699. El tema bien merece un mayor y detenido desarrollo.

El artículo 1411 del Código Civil, tal como está redactado, genera problemas interpretativos porque, de haberse convenido por escrito durante la negociación que el respectivo contrato constará, por ejemplo, por escritura pública, esta última forma adquiriría el carácter de solemnidad, cuya inobservancia derivaría en nulidad. Sin embargo, la validez negocial no es un tema sujeto a la autonomía privada; la ley, sólo la ley y nada más que la ley, es la que define lo que es nulo o no, lo que es anulable o no ${ }^{31}$. Por ello, debe entenderse que lo que regula la norma es lo relativo a la formación del consentimiento, a la existencia del negocio.

Tratándose de ciertos contratos, las partes pueden acordar — de manera escrita y previa - que su celebración quede subordinada a que la voluntad común se exprese de una determinada manera, y como se trata de un tema de existencia, que derivará en una ulterior válida celebración y eficacia negocial, la respectiva forma no puede ser probatoria - esta presupone formación del negocio-, razón por la que se entiende $-y$ se enuncia en el Código Civil de 1984- que la forma debe ser bajo sanción de nulidad. La referencia al requisito de generar una determinada forma bajo sanción de nulidad, no implica que las partes regulen validez o invalidez, sino que descarta que la respectiva forma pueda ser entendida como meramente contingente; se trata de una forma necesaria, sin ella no se generará el consentimiento común.

Encontrándonos ante una presunción resulta manifiesto que no debería olvidarse que la regla general de formación contractual es la consensualidad, siendo la excepción la solemnidad.

Como consecuencia de lo previsto en el artículo 1411 del Código Civil, las partes podrían pactar solemnidades convencionales. La cuestión radica en cuándo y cómo hacerlo. Sobre la base que la regla general es que el perfeccionamiento formativo contractual es consensual, y que la forma solemne contractual fijada legalmente corresponde a normas imperativas, la posibilidad de pactar solemnidades convencionales estaría reservada únicamente para los contratos consensuales. Así, podría convenirse que el arrendamiento sólo existirá si el respectivo acuerdo de voluntades consta por documento de fecha cierta o por escritura pública; pero si no se pacta nada sobre la materia, se aplicará supletoriamente el Código Civil $y$, en ese orden de ideas, el contrato quedará constitutivamente perfeccionado por el simple acuerdo de voluntades. El pacto no será evidentemente procedente tratándose de contratos formales, dado que conforme ya ha sido señalado precedentemente, no resulta posible modificar la forma solemne fijada legalmente

31. Desde la perspectiva de la dogmática jurídica, entendemos que lo relativo a la sanción de invalidez negocial es un tema sujeto a reserva legal, siendo que, sobre la base que un negocio exista, las partes sólo son conceptualmente competentes para pactar sobre su eficacia. Además, siendo la nulidad un remedio por la afectación estructural de un interés que trasciende al de los particulares, de naturaleza general, por afectar a la sociedad misma, resultaría absolutamente cuestionable que las partes —ejerciendo su poder negocial que denota intereses particularespudiesen convenir, o someterse a la presunción relativa, sobre la validez o, expresado de otra manera, sobre la nulidad. La validez está sujeta al principio de legalidad, conforme a la tradición del derecho civil francés a la cual estamos adscritos, por lo que las partes no pueden regular aquello que se encuentra en el ámbito de la reserva legal, carecen simplemente de poder negocial, este no les ha sido reconocido para ello. Otro tema es que las partes puedan establecer, o puedan acogerse a una presunción, sobre cuándo se entiende celebrado el contrato, cuándo se entiende formado el consentimiento. 
bajo sanción de nulidad, ya que se está ante una regla imperativa.

Por ello es que el artículo 1411 del Código Civil exige de un acuerdo "previo", un acuerdo originado antes que nazca - legalmente- aquello que se desea que nazca en una oportunidad distinta, posterior, un acuerdo que se sustentaría en la libertad misma de contratar o no.

Pero no bastaría el acuerdo previo sino que además sería necesario que se pueda acreditar. Siendo que la posibilidad de solemnidades convencionales estaría dirigida a los contratos - supletoriamente-consensuales, en los que al existir libertad de forma se pueden perfeccionar constitutivamente de manera verbal, para efecto de probar lo contrario, esto es, que el simple acuerdo de voluntades aún no determinaría la génesis contractual, debería mediar preferentemente una prueba objetiva, de carácter documental, por ello la ley exige que el acuerdo previo se acredite por escrito como forma probatoria privilegiada -artículo 144 del Código Civil-, aunque a nuestro entender ello no significa que la forma escrita sea el único medio probatorio, ya que no se trata de una forma en que sancione con nulidad su inobservancia.

Por último, el artículo 1411 del Código Civil establecería una presunción relativa sobre solemnidad convencional. Una presunción significa que se asume como cierto aquello respecto de lo cual se carece de certeza, pero se trata de una asunción de certeza de carácter relativo porque permite la prueba en contrario - aunque no se indique expresamente en el texto de la norma bajo comentario-. La regla general en materia de presunciones legales es su carácter relativo; la excepción, es que sean absolutas, lo cual debe estar enunciado en la respectiva norma, impidiendo la prueba en contrario.

Bajo la lectura que el artículo 1411 regula a las solemnidades convencionales, que deben ser acordadas previamente y por escrito, ¿cuál sería la prueba en contrario que impida asumir que el acuerdo sobre forma es sobre una solemnidad? Sería, por ejemplo, el caso cuando se acredita que la forma convenida es de carácter simplemente probatorio, siendo que su conducta contractual es concluyente en el sentido que se aprecia el reconocimiento al nacimiento del contrato, aun cuando no se había cumplido con la observancia de la forma identificada en su oportunidad. De no afectarse la existencia negocial, se podría entender que se está ante una simple forma probatoria, asociada a una ineficacia temporal mientras la misma no sea satisfecha.

Un último comentario que tenemos sobre este tema está relacionado al poder negocial de las partes para regular que su declaración común deba observar una determinada forma, bajo sanción de nulidad, como requisito de existencia negocial.

Sobre el particular, Ferri sostiene lo siguiente:

“Las partes pueden convenir por escrito que
adoptarán determinada forma para la futura
celebración de un contrato; la forma para el
futuro contrato puede ser querida con carác-
ter ad substantiam o ad probationem. Dado
que, como se ha señalado antes, las normas
que prescriben ad substantiam formas de-
terminadas son inderogables, las partes sólo
pueden establecer que el contrato debe reves-
tir una determinada forma cuando la ley no
prescriba ninguna; o bien pueden establecer
que sea adoptada la escritura pública, cuan-
do para la ley sea suficiente el documento
privado. Esto significa que las partes pueden
derogar la normativa legal sobre las formas
con el sólo hecho de volverla más onerosa, es
decir, con la adopción de formas más garan-
tizadas o más solemnes que las dispuestas en
la ley, pero jamás siguiendo el procedimiento
inverso, es decir, disminuyendo la solemni-
dad"32 (el subrayado es nuestro).

Si bien podría entenderse literalmente que el indicado autor señala que la solemnidad con-

32. FERRI, Luigi. "Lecciones sobre el Contrato (Curso de Derecho Civil).'Lima: Editora Jurídica Grijley E.I.R.L., 2004, pp. 131-132. 
vencional resulta procedente si representa una mayor onerosidad o seguridad respecto a la solemnidad legalmente prevista —así, podría convenirse que la fianza sólo existirá en la medida que se otorgue una escritura pública, siendo insuficiente la forma escrita simple, que es la formalidad esencial legal conforme al artículo 1870 del Código Civil-, consideramos que ello sería contradictorio con su propia opinión en el sentido que las normas que prescriben formas sustanciales, esenciales o solemnes son inderogables - ya que poseen carácter imperativo. Entendemos que el texto reproducido no se refiere a las solemnidades propiamente dichas sino a las simples formas probatorias - que también las señala la ley, al igual como lo pueden hacer las partes-, esto es, no se refiere a la formalidad ad solemnitatem - contratos formales-, sino a la de carácter ad probationem - contratos consensuales relativos-, de manera que si la ley establece que la forma a respetarse es la escrita, o la escrita de fecha cierta - como medios privilegiados de prueba-, nada impediría conceptualmente que las partes puedan acordar que el medio idóneo de prueba será una escritura pública.

En síntesis, en el marco de los contratos consensuales, sujetos a libertad de forma, las partes pueden convenir formas probatorias - subordinando, en principio, la eficacia negocial-o solemnes — afectando la existencia, subordinando la formación del consentimiento-, siendo que la ley refiere a una presunción sobre el particular, presunción que debe ser interpretada y aplicada con prudencia, para no afectar la regla general de perfeccionamiento constitutivo consensual.

El profesor Vidal ${ }^{33}$, con relación a la denominada solemnidad de actos jurídicos, reconociendo previamente que puede ser prescrita legalmente o de generación voluntaria, expresa puntualmente lo siguiente en nuestro medio:

"Establecida la distinción que de la forma hace nuestro Código Civil, la inferencia es que el requisito de validez exigido por el numeral 4 de su artículo 140 es el de la forma prescrita con carácter ad solemnitatem, en cuanto precisa que, además de los otros requisitos enumerados, se requiere también de la "observancia de la forma prescrita bajo sanción de nulidad".

Si se atiende a un supuesto apodíctico en cuanto a que no existe acto jurídico sin forma, pues esta - sic - es el aspecto exterior de la manifestación de voluntad, que viene a ser su continente, la conclusión, además, no puede ser otra que la de la forma prescrita en el numeral 4 del artículo 140 es una forma constitutiva, que no puede faltar, porque sin ella no existirá el acto jurídico y, en buena cuenta, es este también el sentido y la función de la forma ad solemnitatem.

Toda forma no es, pues, requisito de validez, aunque si es un elemento de existencia, ya que sin la forma no existe acto jurídico alguno".

Son las propias partes las mejores intérpretes de aquello que convinieron en su oportunidad; ello requiere poner suma atención a los hechos, a las actuaciones de las partes, como manera de exteriorización de la voluntad.

\section{MODIFICACIONES A LOS CONTRATOS SUJETOS A DETERMINADA FORMA}

En materia contractual, con relación a la aplicación del artículo 1413 del Código Civil, la experiencia y las propias discusiones en clase, y como señalamos en trabajos anteriores, pueden presentarse al menos cinco situaciones distintas:

Uno, Otto y Max celebran un contrato de donación inmobiliaria y, encontrándose vigente dicho vínculo, deciden modificar ciertos aspectos contractuales. ¿Deben de observar alguna forma en particular? Debemos considerar que

33. VIDAL RAMÍREZ, Fernando. Op. cit., p. 198. Podrá discreparse sobre si la exigencia de una formalidad sustancial proviene de reglas que interesen al orden público, pero se concuerda plenamente en que la exigencia de una forma con fin específico, sancionado con nulidad en caso de inobservancia, es dar existencia al negocio, para que la voluntad sea generada de manera conforme al ordenamiento, sea concomitantemente válida. 
la donación inmobiliaria es un contrato formal o que exige de una formalidad ad solemnitatem.

Dos, Otto y Max celebran por escrito un contrato de suministro oneroso $y$, encontrándose vigente el referido contrato, acuerdan modificar determinados aspectos del mismo. ¿Deben de observar alguna forma para generar su voluntad común? Debemos considerar que si bien estamos ante un contrato consensual, el mismo, de ser el caso, está sujeto a una formalidad probatoria.

Tres, Otto y Max celebran un comodato y deciden que el mismo, para todo efecto probatorio, constará por escritura pública, siendo de manera sobreviniente que deciden modificar el contrato. ¿Deben de observar alguna forma? Debemos considerar que si bien estamos ante un contrato sujeto a una formalidad legal ad probationem, las partes han acordado una formalidad probatoria más onerosa: una escritura pública y no un simple documento.

Cuatro, Otto y Max celebran un arrendamiento, el mismo que luego es elevado a escritura pública y, encontrándose también vigente dicho vínculo, acuerdan determinadas modificaciones, ¿Deben cuidar de observar alguna forma en especial? Aunque el arrendamiento es un contrato consensual absoluto, las partes habrían acordado, de hecho, una formalidad convencional ad probationem.

Y cinco, por último, nuestros tantas veces mencionados Otto y Max celebran una compraventa, con carácter verbal y, encontrándose vigente dicho vínculo acuerdan ciertas modificaciones, ¿Deben cuidar de observar alguna formalidad en especial? Debemos considerar que estamos ante un contrato consensual, ante un consensual absoluto, celebrado bajo la más amplia libertad de forma.

No tenemos duda alguna que, en el primer caso, existiendo de por medio el concepto de formalidad consustancial, las modificaciones contractuales tienen que observar los mismos requisitos exigidos para la válida celebración contractual. En ese orden de ideas, la declaración de voluntad con relación a una donación in- mobiliaria es calificada para todo efecto, siendo que la regla enunciada se aplica tratándose por igual de una solemnidad legal o convencional, ya que en ambos casos la declaración de voluntad sólo se entiende exteriorizada cuando se cumple con la forma pertinente. El tema no merece mayor comentario. Resulta obvio que el artículo 1413 del Código Civil, reproducido al inicio del presente trabajo, no puede referirse a esta hipótesis de trabajo. En derecho, las cosas se modifican, o se extinguen, de la misma manera en que se generan.

Tratándose del segundo caso surge la cuestión. Si la ley establece que la forma escrita — que es una de las tres formas previstas legalmente en materia contractual - es un medio para probar la existencia del acto, específicamente el medio preferido para acreditar existencia y contenido, conforme postulamos en la parte pertinente del presente trabajo, resulta manifiesto que dicha formalidad debería ser observada para fines de dejar constancia de las modificaciones acordadas, siendo que en caso pudiese acreditarse dichas modificaciones por otros medios, lo que será preferido es lo escrito. En caso que las partes no observasen la señalada formalidad, ello no significará que no pueda demostrarse la existencia y contenido de la modificación contractual a través de otros medios, conforme ya hemos analizado.

En ese orden de ideas, lo sancionado en el artículo 1413 del Código Civil adquiere relevancia en el escenario que, de generarse un concurso de medios probatorios, se prefiera lo que está por escrito. El legislador recomienda, por lo tanto, que las modificaciones acordadas consten también por escrito, conforme al artículo 1605 del Código Civil.

Forma preferida o recomendada, no es forma necesaria; una cosa es optar por un determinado medio probatorio, y otra cosa es asumir que no existe tal concurso, porque la voluntad sólo puede declarada de una sola manera para que se reconocida por el ordenamiento.

El tercer caso es esencialmente la misma situación objeto del segundo caso, sólo que posee un elemento particular: las partes han acordado una

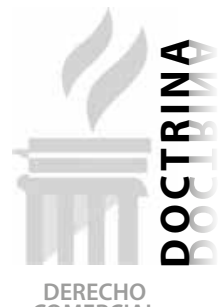


formalidad más gravosa a la legalmente prevista. No tenemos duda que ello es jurídicamente posible por la naturaleza probatoria de la formalidad, distinto sería el caso de la formalidad esencial.

Conforme hemos analizado precedentemente, dado que el carácter ad solemnitatem se deriva de una norma imperativa, no resulta posible pactar válidamente cosa distinta: "Las partes pueden volver formales negocios que por ley no lo son, en uso de la autonomía de la voluntad (...). Pero no podrán, en cambio, dejar de lado las solemnidades dispuestas por el legislador ad substantiam, por estar de por medio un interés público" ${ }^{\prime 34}$.

En dicho sentido, si la ley establece como formalidad probatoria la simple forma escrita, y las partes acuerdan que esa forma escrita sea una escritura pública, consideramos que lo que predomina es la voluntad de las partes $y$, en ese orden de ideas, dado que ellas mismas han identificado como medio de acreditación de existencia y contenido del contrato a la escritura pública, esta debería ser preferida para el caso propuesto por una razón de consecuencia. Estamos, en pocas palabras, ante un tema de aplicación de norma supletoria, siendo que en el caso propuesto por no haber "laguna contractual" no corresponde pretender que prevalezca la ley respecto a la propia declaración de las partes.

Por lo tanto, las modificaciones pactadas deberían constar para fines probatorios en escritura pública, forma que será preferida en caso de un conflicto de medios probatorios, aunque se estará finalmente al querer de las partes sobre la materia, ya que en cualquier caso no estamos ante solemnidades.

Conforme al cuarto caso, las partes habrían acordado de hecho una formalidad probatoria tratándose de lo que, en principio, es un contrato consensual puro; en ese orden de ideas, las modificaciones deberían cumplir, por la misma razón de consecuencia anteriormente comen- tada, con la misma forma observada tratándose del contrato original.

El problema radica en que, conforme se desprende de la redacción del artículo 1413 del Código Civil, pareciera que la conclusión contenida en el párrafo anterior no es la adecuada. Nos explicamos, el señalado artículo establece que las modificaciones del contrato original deben cumplir con la misma forma "prescrita" para este último. Al respecto, el término"prescrita" se asocia a una expresa disposición legal - conforme se aprecia de la redacción del artículo 1412 del Código Civil, en la que el legislador claramente distingue entre formalidad "prescrita" legalmente y formalidad "convenida" por las partes-; en ese orden de ideas, en el caso analizado, dado que el arrendamiento no es un contrato consensual relativo - sujeto a la observancia de una determinada forma con fines probatorios-, llegaríamos a la conclusión que, si el contrato presenta una forma probatoria convencional, la misma no requiere observarse para fines de sus modificaciones.

No obstante, de acuerdo a la Exposición de Motivos elaborada por quienes fueron miembros de la denominada "Comisión Reformadora" del Código Civil, se indica expresamente cosa distinta, ya que al comentar los alcances del artículo 1413 del Código Civil, Arias Schreiber expresa: "Tomemos como ejemplo el arrendamiento de un inmueble. Si las partes estipularon que el contrato fuese formalizado por escritura pública, cualquier modificación del mismo deberá ceñirse a esta forma para que tenga validez" ${ }^{\prime 35}$. En otras palabras, el artículo 1413 se aplicaría no sólo para contratos consensuales relativos sino inclusive para los contratos consensuales puros, en que las partes, sobre la base de la libertad de forma, acordaron expresarse de una determinada forma y no otra.

Suscribimos lo expresado por el desaparecido profesor Arias Schreiber. En efecto, el pacto sobre formalidad puede ser expreso o tácito; pue-

34. MOSSET, Jorge. Op. cit., p. 260.

35. ARIAS SCHREIBER, Max. "Exposición de Motivos y Comentarios - Contratos en general", en: REVOREDO DE DEBAKEY, Delia, "Código Civil, tomo VI (Exposición de Motivos y Comentarios)". Lima: Okura Editores S.A., 1985, p. 73. 
de ser que en el documento contractual - de existir - las partes no expresen un ápice sobre el tema, pero convienen que el contrato presente determinada forma -escritura pública, en el caso propuesto-, por lo que se estaría ante una forma de carácter ad probationem, dado que no se aprecia naturaleza esencial. Desde ese punto de vista, dado que la forma probatoria entraña generar un medio privilegiado de acreditación del negocio, en razón que el contrato original consta de determinada forma, la misma debería considerarse para fines de cualquier modificación con el objeto de solucionar preventivamente cualquier posible conflicto entre los distintos medios probatorios del acuerdo modificatorio de los cuales podría hacerse uso.

Sobre este particular, merece destacarse que, en el caso propuesto, si bien la formalidad ad probationem no tiene origen legal, sí posee carácter convencional, siendo que más allá de la fuente estamos siempre ante una formalidad no esencial, meramente probatoria. En ese orden de ideas, estimamos que convendría precisar en el texto del artículo 1413 del Código Civil, que la forma del contrato original puede ser legalmente prescrita o convencionalmente acordada ${ }^{36}$. Se ganaría en claridad.

Un último comentario respecto a lo expresado por Arias Schreiber en la cita anteriormente reproducida. Indica que cualquier modificación del contrato original deberá ceñirse a la forma probatoria del contrato original "para que tenga validez". Discrepamos si se lee el texto "textualmente". La inobservancia de la formalidad probatoria no deriva en invalidez, porque de lo contrario no estaríamos ante un tema de formalidad ad probationem sino ad solemnitatem. Retomamos lo ya explicado precedentemente en el sentido que el lenguaje puede ser lato o estricto, y siendo que el término "validez" es polisémico, esa "validez" puede, y debe, ser en- tendida contextualmente como eficacia, como "valor" en la acepción de generación efectos. Habría una presunción implícita de ineficacia; empero, ello no impide que pueda recurrirse, en el universo de medios probatorios, a alguna manera o forma de probar la eficacia negocial.

Por último, tratándose del quinto caso, somos de la opinión que tratándose de contratos consensuales puros, que se perfeccionan constitutivamente por el simple acuerdo de voluntades, por lo que es legalmente suficiente el acuerdo verbal, las modificaciones pueden realizarse observándose cualquier forma, cualquier forma documental, sin restricción alguna, por lo que no tiene que cumplirse necesariamente con la primigenia. Conforme a ello, un contrato verbal puede modificarse por escrito y viceversa; un contrato celebrado bajo una determinada forma documental puede modificado por otra de distinta dimensión, etc., salvo desde luego que las partes hubiesen acordado determinados condicionantes para generar la eficacia en cuestión, en el marco de la autonomía privada.

Atendiendo a lo expresado, cabe cuestionarse sobre si se justifica o no realizar alguna precisión normativa el al artículo 1413 del Código Civil, ¿Convendría precisar en el texto que la forma del contrato original puede ser legalmente prescrita o convencionalmente acordada?, la respuesta puede positiva, como ya hemos afirmado se ganaría en claridad; empero, ¿es necesario?, respuesta negativa.

En ese contexto mantienen vigencia las palabras De la Puente ${ }^{37}$, contenidas significativamente en la parte final de su magna obra "El contrato en general", cuando nos expresa:

"No quiero terminar esta obra sin expresar una preocupación que me desasosiega. Pese a considerar que la Sección Primera del Libro

36. Resulta pertinente remitirnos a los antecedentes del artículo 1413 del Código Civil, en el sentido que la ponencia original hacía referencia a "forma prescrita — legalmente - o utilizada — por acuerdo expreso o tácito". Cfr: DE LA PUENTE, Manuel. Op. cit. p. 477.

37. DE LA PUENTE Y LAVALLE, Manuel. Op. cit. Tomo III, pp. 667-668. 
VII del Código civil constituye un excelente conjunto de disposiciones que de manera coherente profundiza con responsabilidad la problemática de la contratación moderna, debo reconocer que como toda factura humana, adolece de defectos que afean la obra legislativa. Frente a estos incuestionables defectos, existe una corriente de opinión que, no obstante su loable mérito en destacarlos, se orienta a corregirlos mediante la modificación o supresión de las normas jurídicas correspondientes. Pienso que debemos afrontar una realidad. Los Códigos no son una secuencia de disposiciones colocadas caprichosamente unas al lado de las otras, sino un todo orgánico en que cada una de sus normas, especialmente las que integran cada Sección, responde a un plan integral que las vincula íntima y ordenadamente, de tal manera que el cambio o supresión de una de ellas rompe la armonía del conjunto. Como los Códigos no pueden sustituirse rápidamente, pues son redactados con una vocación de permanencia, pienso que el camino adecuado es tomar una actitud más positiva e intentar la interpretación de la norma cuestionada utilizando especialmente los medios o elementos lógico y sistemático, para otorgarle su verdadero sentido a través de su relación con las demás en su conjunto. Sólo asílograremos conservar nuestro Código de acuerdo a la concepción que lo inspiró, adecuando meditadamente su espíritu a la constante evolución del Derecho, sin restarle coherencia y unidad. Es admirable, en este sentido, la jurisprudencia francesa que ha logrado actualizar el viejo Código Napoleón, sin necesidad de recurrir a cambios legislativos superables.

Únicamente si se detectan verdaderos errores conceptuales innatos, que resulten insalvables de otro modo, será menester tomar el duro camino de la modificación radical. De igual manera, esa medida deberá tomarse si el devenir nos depara tales cambios ideológicos en la noción del Derecho contractual que la reestructuración de su manifestación positiva sea inevitable para adecuarse a la nueva realidad" (el subrayado es nuestro).
Encontrándose en proceso de revisión el Código Civil, con la posibilidad de introducir modificaciones, viene a la memoria lo que en alguna oportunidad me expresó un reconocido abogado, en el sentido que la "cereza del pastel" para todo jurista era resolver controversias, porque en esa oportunidad aplicaría su conocimiento y experiencia, de manera que "diría" derecho, aunque también reconocía que era una gran tentación, porque es una función que demanda de especial responsabilidad y preparación, por lo que no debería ejercerse si se carece de especialización y disposición. De igual manera, la "cereza del pastel" para una carrera docente sería desempeñarse como legislador, pero la gran tentación es priorizar nuestro ego respecto de lo que debe evaluarse para concluir serenamente si es necesaria o no una modificación legislativa, a la luz de la experiencia jurisdiccional.

Por ello, la invocación "Et ne nos indvcas in tentationem" adquiere singular significado.

\section{A MODO DE CONCLUSIÓN}

La autonomía voluntad no es irrestricta, no estamos sujetos al denominado voluntarismo, hay materias que no pueden ser materia de autorregulación, pese a que el ordenamiento reconozca que las partes son las grandes e inmediatas protagonistas del intercambio económico en una economía social de mercado; en consecuencia, al analizar lo relativo a la formación del consentimiento, y a la manera en que este se expresa para dar origen a la relación jurídico patrimonial de naturaleza obligacional, debemos tener en consideración que las partes carecen de poderes negociales para regular la validez del acto celebrado o por celebrar, aunque nada impide que sí puedan hacerlo tratándose de su existencia y eficacia.

Conforme a ello, no resulta viable jurídicamente promover la celebración real de contratos, más sí aceptar la celebración formal de fuente voluntaria, ya que la misma se encuentra finalmente autorizada y regulada por una presunción legal que debe aplicarse restrictivamente para no afectar la regla general de formación contractual consensual.

Ello debe contextualizar nuestra lectura e interpretación del Código Civil de 1984 en materia de forma contractual. 